\title{
Calcium-independent astrocytic lipid release modulates neuronal excitability
}

Fushun Wang ${ }^{1,2}$, Heather B. Bradshaw ${ }^{3}$, Salvador Pena ${ }^{4}$, Beata Jablonska ${ }^{5}$, Julia Xavier $^{6}$, Sheng Gong ${ }^{7}$, Baoman $\mathrm{Li}^{1}$, Devin Chandler-Militello ${ }^{1}$, Lane K. Bekar ${ }^{8}$, and Nathan A. Smith ${ }^{5,9,10^{*}}$

${ }^{1}$ Departments of Neurosurgery and Neurology, University of Rochester School of Medicine and Dentistry, Rochester, NY 14642, USA.

${ }^{2}$ Institute of Brain and Psychological Sciences, Sichuan Normal University, Chengdu, Sichuan 610060, China.

${ }^{3}$ Department of Psychological and Brain Sciences, Indiana University, Bloomington, IN 47405, USA

${ }^{4}$ Department of Pathology, University of Rochester School of Medicine and Dentistry, Rochester, NY 14642, USA

${ }^{5}$ Center for Neuroscience Research, Children's National Research Institute, Children's National Hospital, Washington DC 20010, USA.

${ }^{6}$ George Washington University, Washington DC 20052, USA.

${ }^{7}$ Department of Physiology and Biophysics, Case Western Reserve University School of Medicine, Cleveland, OH 44106, USA

${ }^{8}$ Department of Anatomy, Physiology, and Pharmacology, University of Saskatchewan, Saskatoon, SK S7N 5E5.

${ }^{9}$ George Washington University School of Medicine and Health Sciences, Washington DC 20052, USA.

${ }^{10}$ Lead Contact

${ }^{*}$ Correspondence should be addressed to Dr. Nathan Anthony Smith, Email:nasmith2@childrensnational.org, Twitter: @SmithLab2018 


\section{ABSTRACT}

Accumulating data point to a key role of $\mathrm{Ca}^{2+}$-dependent gliotransmitter release as a modulator of neuronal networks. Here, we tested the hypothesis that astrocytes in response to agonist exposure also release lipid modulators through activation of $\mathrm{Ca}^{2+}$-independent phospholipase $\mathrm{A}_{2}$ (iPLA $)_{2}$ activity. We found that cultured rat astrocytes treated with selective ATP and glutamatergic agonists released arachidonic acid (AA) and/or its derivatives, including the endogenous cannabinoid 2-arachidonoyl-sn-glycerol (2AG) and prostaglandin E2 (PGE $)$. Surprisingly, buffering of cytosolic $\mathrm{Ca}^{2+}$ resulted in a sharp increase in agonist-induced astrocytic lipid release. In addition, astrocytic release of $\mathrm{PGE}_{2}$ enhanced miniature excitatory post-synaptic potentials (mEPSPs) by inhibiting the opening of neuronal Kv channels in brain slices. This study provides the first evidence for the existence of a $\mathrm{Ca}^{2+}$-independent pathway regulating the release of $\mathrm{PGE}_{2}$ from astrocytes, and furthermore demonstrates a functional role for astrocytic lipid release in the modulation of synaptic activity.

\section{Significance Statement}

Until now, the majority of studies implicating astrocytes in modulating synaptic activity have focused on $\mathrm{Ca}^{2+}$-dependent release of traditional gliotransmitters such as D-serine, ATP, and glutamate. Mobilization of intracellular stores of $\mathrm{Ca}^{2+}$ occurs within a matter of seconds, but this novel $\mathrm{Ca}^{2+}$-independent lipid pathway in astrocytes could potentially occur on a still faster time scale and thus participate in the rapid signaling processes involved in synaptic potentiation, attention, and neurovascular coupling. 


\section{INTRODUCTION}

Comprising the major part of the dry weight of adult brain, lipids are an essential component of the phospholipid bilayer, mainly occurring as long-chain polyunsaturated fatty acids (PUFA) such as arachidonic acid (AA) and docosahexanoic acid (DHA) (Sinclair, 1975). The liver is the major site of AA synthesis, but the brain can produce AA and DHA in situ from their precursor fatty acids, linoleic and linolenic acids (Dhopeshwarkar and Subramanian, 1976). Astrocytes play a central role in the synthesis of $A A$ and DHA in brain. Through their vascular endfeet, astrocytes have prime access to fatty acid precursors arriving across the blood-brain barrier (BBB), and serve as the major site for processing the essential fatty acids in the central nervous system (CNS) (Moore, 1993). Astrocytes also play a key role in macroscopic distribution of lipids in the brain parenchyma via perivascular glymphatic flux (Rangroo Thrane et al., 2013a; Plog and Nedergaard, 2018).

Lipids have gained much attention for their role as bioactive mediators in the CNS (Carta et al., 2014; Ledo et al., 2019). Numerous studies have focused on lipids in relation to functional hyperemia and synaptic activity. For instance, $\mathrm{PGE}_{2}$ is a potent vasodilator and vasoconstrictor regulating CNS blood flow (Zonta et al., 2003; Takano et al., 2006; Gordon et al., 2007; Dabertrand et al., 2013; MacVicar and Newman, 2015; Czigler et al., 2019), and modulates the membrane excitability of CA1 pyramidal neurons during synaptic activity (Chen and Bazan, 2005). Furthermore, AA and its derivatives are important intracellular second messengers that can modulate the activities of various ion channels (Piomelli, 1993; Meves, 1994; Horimoto et al., 1997; Boland and Drzewiecki, 2008; Cordero-Morales and Vasquez, 2018). In addition, $\mathrm{PGE}_{2}$ can suppress the outwardly rectifying Kv current in sensory neurons (Nicol et al., 1997; Evans et al., 1999), whereas AA suppresses Kv channels in the soma or dendrites of pyramidal neurons, and consequently broadens their presynaptic action potentials (Carta et al., 2014) and enhances EPSPs (Ramakers and Storm, 2002). However, those studies focused on the effects of neuronal lipid release effects on synaptic activity and paid scant attention to receptor 
mediated pathways by which astrocytic lipids might influence synaptic activity. Given that the majority of AA, DHA, and other lipids present in the extracellular fluid is produced by astrocytes (Moore et al., 1991), receptor-mediated release could be a significant factor in the modulation of synaptic activity.

In culture, astrocytes can release $\mathrm{AA}$ in a $\mathrm{cPLA}_{2} \mathrm{Ca}^{2+}$-dependent pathway upon activation of metabotropic glutamate (mGluR) and P2Y purine (ATP) receptors (Bruner and Murphy, 1990; Stella et al., 1994; Stella et al., 1997; Chen and Chen, 1998). In addition, astrocytes also express the $\mathrm{Ca}^{2+}$-independent $\mathrm{PLA}_{2}$ (iPLA ${ }_{2}$ ) enzyme (Sun et al., 2005). Both of these isoforms are activated by the G-protein $\beta y$ subunit (Jelsema and Axelrod, 1987; Murayama et al., 1990; van Tol-Steye et al., 1999), but iPLA2 does not require $\mathrm{Ca}^{2+}$ or PKC phosphorylation for its activation (Winstead et al., 2000). Receptor-stimulated iPLA $\mathrm{A}_{2}$ activation can release AA and DHA in numerous cell types (Gross et al., 1993; Portilla et al., 1994; Akiba et al., 1998; Seegers et al., 2002; Tay and Melendez, 2004), but has not been fully explored in the case of astrocytes.

Previous work in our laboratory and elsewhere has demonstrated that astrocytes are capable of releasing gliotransmitters upon stimulation with mGluR or ATP receptor agonists, but the impact of this signaling on synaptic activity remains controversial. Recent studies with genetically encoded calcium indicators enabled us to identify localized $\mathrm{Ca}^{2+}$ signals within astrocytic fine processes and have confirmed $\mathrm{Ca}^{2+}$-dependent astrocytic effects on synaptic activity (Yu et al., 2018). However, the existence of $\mathrm{Ca}^{2+}$-independent lipid signaling in astrocytes is still not clearly established. Therefore, in this study we tested the hypothesis that astrocytes could support $\mathrm{Ca}^{2+}$-independent lipid signaling to modulate synaptic transmission. We used $\mathrm{Ca}^{2+}$ chelation to show that ATP and mGluR agonism can release lipids through $\mathrm{iPLA}_{2}$ activation, resulting in the potentiation of synaptic activity. Because we currently lack the tools to assess $\mathrm{Ca}^{2+}$-independent signaling in astrocyte fine processes adjacent to synapses, we use $\mathrm{Ca}^{2+}$ inhibition on a grand scale to unmask this phenomenon (see discussion). 


\section{MATERIALS and METHODS}

\section{Culture}

Cultured neocortical astrocytes were prepared from postnatal day 1 or 2 Wistar rat pups (Taconic Farms, Inc.) of either sex, as previously described (Lin et al., 1998). In brief, cerebral cortices were dissected on ice, and the meninges removed. The tissue was washed three times in $\mathrm{Ca}^{2+}$-free Hanks' balanced salt solution, and then triturated, filtered through a $70 \mu \mathrm{m}$ nylon mesh, and centrifuged. The pellet was resuspended in $10 \%$ fetal bovine serum in Dulbecco's modified Eagle's medium (DMEM)/F12 containing penicillin (100 IU ml ${ }^{1}$ ) and streptomycin (100 $\mu \mathrm{g} \mathrm{ml}{ }^{-1}$ ), and transferred to culture flasks. Cells were maintained at $37^{\circ} \mathrm{C}$ in an incubator containing humidified air and $5 \% \mathrm{CO}_{2}$. The medium was changed after $24 \mathrm{hrs}$ and twice a week thereafter. More than $95 \%$ of the cells immunostained positive for GFAP. When the cells became confluent, they were rinsed two times in $\mathrm{Ca}^{2+}$-free Hanks' balanced salt solution, suspended in $0.05 \%$ trypsin-containing PBS for $1 \mathrm{~min}$, resuspended in DMEM/F12, centrifuged to remove the trypsin-containing supernatant, and then plated in 24-well plates. Experiments were performed when the cells were $95 \%$ confluent.

\section{Viral Vectors and Viral Transductions}

Viral vectors driving GFAP cyto-GCaMP6f (Baljit S. Khakh) were obtained from the University of Pennsylvania Vector Core (AAV 2/5 serotype). Secondary rat astrocytic cultures were transduced with AAV GFAP cyto-GCaMP6f. After transduction, the cultures were incubated at 37 ${ }^{\circ} \mathrm{C}$ for 5 days prior to $\mathrm{Ca}^{2+}$ imaging experiments.

\section{$\mathrm{Ca}^{2+}$ imaging}

Cultured cells in 24-well plates were transduced with AAV GFAP cyto-GCaMP6f and incubated with various pharmacological agents for 30 minutes at $37{ }^{\circ} \mathrm{C}$. Using confocal microscopy (Olympus FV500), calcium wave activity was evoked by adding an equal volume of medium containing $100 \mu \mathrm{M}$ of ATP to each well. Relative increases in fluorescence signal evoked by P2Y 
receptor agonist exposure over baseline fluoresce $(\Delta F / F)$ were calculated as previously described (Nedergaard, 1994; Smith et al., 2018).

\section{Radiolabeling and Assessment of AA Release}

Confluent rat astrocytic cultures were incubated with $100 \mathrm{nCi}\left[5,6,8,9,11,12,14,15-{ }^{3} \mathrm{H}\right]-\mathrm{AA}$ (PerkinElmer) overnight before the experiments. The cells were washed three times with serum-free medium, and then allowed to recover for 20 minutes. Before stimulation of P2Y receptors with $100 \mu \mathrm{M}$ ATP, the cells were incubated with appropriate inhibitors for 10 to 12 minutes. Aliquots of medium were taken 15 minutes after agonist stimulation, and ${ }^{3} \mathrm{H}-\mathrm{AA}$ and/or its metabolites were measured by liquid scintillation counting.

\section{HPLC/MS/MS analysis of lipids}

Confluent rat astrocytes were washed with serum-free media and then allowed to recover for 1 $\mathrm{hr}$ in serum-free media. At this time, cells were incubated with vehicle or $20 \mu \mathrm{M}$ cyclopiazonic acid (CPA) for 15 minutes and then challenged with $100 \mu \mathrm{M}$ of ATP or vehicle for 15 minutes, as in the above $\left[{ }^{3} \mathrm{H}\right]-\mathrm{AA}$ experiments. Media was then removed and put aside, and $2 \mathrm{ml}$ of HPLCgrade methanol was added to the flask for 5 minutes, and then removed and out aside. An additional $2 \mathrm{ml}$ of HPLC-grade methanol was added, cells were scraped from the sides of the flask, and the contents added to the previous two retained fractions. Deuterìum standards were added to a final concentration of $200 \mathrm{pM}$, and the samples were centrifuged at $19,000 \times \mathrm{g}$ and $24{ }^{\circ} \mathrm{C}$. Lipids in the eluent were partially purified on $500 \mathrm{mg} \mathrm{C18}$ Bond Elut solid phase extraction columns (Varian), concentrated into fractions of $40,60,85$, and $100 \%$ methanol, then analyzed using HPLC/MS/MS (Shimadzu SCL10Avp-Wilmington, DE, USA; API 3000 Applied Biosystems/MDS SCIEX, Foster City, CA, USA) as previously described (Leishman et al., 2018). Over 50 lipids were targeted in these analyses, including 40 lipoamines, 3 acylglycerols, 2 free fatty acids, and 2 prostaglandins (namely $X$ and $Y$ ). It was determined in pilot studies that 
the analyte concentrations were too low for reliable detection in the medium alone, but the extraction of medium and cells together gave sufficient lipid concentrations for reliable assay.

\section{$\mathrm{PGE}_{2}$ Release Assessment via PGE $\mathrm{PG}_{2}$ Imunoassay}

Confluent rat astrocytic cultures were washed 3 times with serum-free medium, and then allowed to recover for 20 minutes. Before stimulation with $100 \mu \mathrm{M}$ ATP, the cells were incubated with appropriate P2Y inhibitors for 10 to 12 minutes. Aliquots of the medium were collected 15 minutes after stimulation and analyzed for PGE2 content uising an immunoassay kit (Cayman Chemicals) following the manufacturer's instructions.

\section{Western Blot}

Protein in samples harvested from the 24-well plates were separated by SDS-PAGE and transferred to a nitrocellulose membrane, which was then blocked with Tris-buffered saline containing $0.05 \%$ (wt/vol) Tween 20 and 5\% nonfat dry milk. The primary antibodies were antiiPLA2 (Sigma, St. Louis, MO), anti- $\beta$-actin (Cell Signaling, Danvers, MA), at 1:1000 to 1:2000 dilutions in blocking buffer. Detection of chemiluminescence from horseradish peroxidase-linked secondary antibodies was performed using the ChemiDoc ${ }^{\mathrm{TM}} \mathrm{XRS}+$ System and running Image Lab ${ }^{T M}$ software.

\section{Isolation of human fetal astrocytes}

Human fetal forebrain tissues were obtained from second-trimester aborted fetuses of 20 weeks gestational age. Tissues were obtained from aborted fetuses, with informed consent and tissue donation approval from the mothers, under protocols approved by the Research Subjects Review Board of the University of Rochester Medical Center. No patient identifiers were made available to or known by the investigators; no samples with known karyotypic abnormalities were included. The forebrain tissue samples were collected and washed 2-3 times with sterile Hank's balanced salt solution containing $\mathrm{Ca}^{2+} / \mathrm{Mg}^{2+}\left(\mathrm{HBSS}^{+/+}\right)$. The cortical plate region (CTX) of the fetal forebrain was dissected and separated from the ventricular zone/subventricular zone (VZ/SVZ) portion. The CTX was then dissociated with papain as previously described (Keyoung 
et al., 2001). The cells were resuspended at a density of $2-4 \times 10^{6}$ cells $/ \mathrm{ml}$ in DMEM/F12 supplemented with N2, $0.5 \%$ FBS, and $10 \mathrm{ng} / \mathrm{ml} \mathrm{bFGF}$ and plated in suspension culture dishes. The day after dissociation, cortical cells were recovered and subjected to magnetic activated cell sorting (MACS) to purify the astrocyte progenitor population. The recovered cells were briefly incubated with CD44 microbeads as per the manufacturer's recommendations (Miltenyi Biotech). The cells were then washed, resuspended in Miltenyi Washing buffer, and bound to a magnetic column (Miltenyi Biotech). The bound CD44+ astrocyte progenitor cells were eluted, collected, and then washed with DMEM/F12. The purified human fetal astrocyte progenitors were cultured in DMEM/F12 supplemented with N2, and 5\% FBS to differentiate them further. To prepare culture dishes for PGE2 immunoassays or immunocytochemistry, the fetal cortical astrocytes were dissociated with TrypLE (Invitrogen) into single cells and then plated onto polyL-ornithine/laminin-coated 24 -well plates $(50,000$ cells per well).

\section{shRNA Lentiviral knockdown of iPLA $A_{2}$ in astrocytes}

Rat astrocytes cultures were plated in a 24-well plate and grown to approximately $50 \%$ confluence. Following the manufacturer's instructions with minor modifications, the cultures were transduced overnight by adding either group VI iPLA 2 shRNA ( $r$ ) lentiviral particles (sc270117-V) or control shRNA lentiviral particles-A (sc-108080) directly to the culture medium containing polybrene (sc-134220) (all from Santa Cruz Biotechnology, Santa Cruz). At 24 hours after transfection, the culture medium was removed, and fresh culture medium without polybrene was added. Experiments and Western blot analysis were performed 7 days after transduction.

\section{Acute Hippocampal Slice Preparation and Electrophysiology}

Unless otherwise noted, 15-21 day old C57BL/6 (Charles River, Wilmington, MA), MrgA1 ${ }^{+/-}$ transgenic, and littermate control MrgA $1^{-/-}$pups (courtesy of Dr. Ken McCarthy) (Fiacco et al., 2007) of either sex were used for the preparation of hippocampal slices as previously described (Wang et al., 2012). The pups were anesthetized in a closed chamber with isoflurane (1.5\%) 
and decapitated. The brains were rapidly removed and immersed in an ice-cold cutting solution that contained (in mM): 230 sucrose, $2.5 \mathrm{KCl}, 0.5 \mathrm{CaCl}_{2}, 10 \mathrm{MgCl}_{2}, 26 \mathrm{NaHCO}_{3}, 1.25 \mathrm{NaH}_{2} \mathrm{PO}_{4}$, and 10 glucose, $\mathrm{pH}=7.2-7.4$. Coronal slices $(400 \mu \mathrm{m})$ were cut using a vibratome (Vibratome Company, St. Louis) and transferred to oxygenated artificial cerebrospinal fluid (aCSF) that contained (in mM): $126 \mathrm{NaCl}, 4 \mathrm{KCl}, 2 \mathrm{CaCl}_{2}, 1 \mathrm{MgCl}_{2}, 26 \mathrm{NaHCO}_{3}, 1.25 \mathrm{NaH}_{2} \mathrm{PO}_{4}$, and 10 glucose, $\mathrm{pH}=7.2-7.4$ (osmolarity $=310 \mathrm{mOsm}$ ). Slices were incubated in this aCSF for $1-5$ hours at room temperature before electrophysiological recording. Experiments were performed at room temperature $\left(21-23^{\circ} \mathrm{C}\right)$. During the recordings, the slices were placed in a perfusion chamber and superfused with aCSF gassed with $5 \% \mathrm{CO}_{2}$ and $95 \% \mathrm{O}_{2}$ at room temperature. Cells were visualized with a $40 \mathrm{X}$ water-immersion objective and differential inference contrast (DIC) optics (BX51 upright microscope, Olympus Optical, New York, NY). Patch electrodes were fabricated from filament thin-wall glass (World Precision Instruments) on a vertical puller; the pipette's resistance was around 6-9 $\mathrm{M} \Omega$ with addition of intracellular pipette solution. The pipette solution contained (in mM) $140 \mathrm{~K}$-gluconate, 5 Na-phosphocreatine, $2 \mathrm{MgCl}_{2}$, $10 \mathrm{HEPES}, 4 \mathrm{Mg}$ ATP, $0.3 \mathrm{Na}-\mathrm{GTP}$ ( $\mathrm{pH}$ adjusted to 7.2 with $\mathrm{KOH}$ ). The current-voltage relationship (I-V curve) of voltage-gated potassium currents was recorded under voltage-clamp using an AxoPatch MultiClamp 700B amplifier (Axon Instruments, Forster City, CA). When measuring outward currents, QX314 (0.5 mM) was added to the pipette solution to block $\mathrm{Na}^{+}$currents. For recordings of miniature excitatory post-synaptic potentials (mEPSPs), $0.5 \mu \mathrm{M} \mathrm{TTX}$ was added to the aCSF. The junction potential between the patch pipette and bath solution was zeroed before forming a giga-seal. Patches with seal resistances less than $1 \mathrm{G} \Omega$ were rejected. Data were low-pass filtered at $2 \mathrm{kHz}$ and digitized at $10 \mathrm{kHz}$ with a Digidata 1440 interface controlled by pClamp Software (Molecular Devices, Union City, CA).

\section{Pharmacological agents used in cultures and slice experiments}

Adenosine 5 -triphosphate (ATP, $100 \mu \mathrm{M})$; Cyclopiazonic acid (CPA, $20 \mu \mathrm{M})$; trans- (1S, 3R)-1Amino-1, 3-cyclopentanedicarboxylic acid (t-ACPD, $100 \mu \mathrm{M}) ; \quad( \pm)$-a-Amino-3-hydroxy-5- 
methylisoxazole-4-propionic acid hydrobromide (( \pm )-AMPA, $100 \mu \mathrm{M})$; Prostaglandin $\mathrm{E}_{2}\left(\mathrm{PGE}_{2}\right.$, $50 \mu \mathrm{M}$, Tocris); Phe-Met-Arg-Phe amide (FMRF, $15 \mu \mathrm{M})$; Thr-Phe-Leu-Leu-Arg-NH $\mathrm{N}_{2}$ (TFLLR$\mathrm{NH}_{2}, 30 \mu \mathrm{M}$, Tocris); N-Acetyl-Asp-Glu (NAAG, $\left.100 \mu \mathrm{M}\right) ;(1 R, 4 R, 5 S, 6 R$ )-4-Amino-2-oxabicyclo [3.1.0] hexane-4,6-dicarboxylic acid disodium salt (LY379268, $100 \mu \mathrm{M}$, Tocris); calmidazolium chloride (CMZ, $2 \mu \mathrm{M}$, Tocris); methyl arachidonyl fluorophosphonate (MAFP, $10 \mu \mathrm{M}$ ); bromoenol lactone (Bel, $10 \mu \mathrm{M}) ; \mathrm{AA}(50 \mu \mathrm{M}) ; N$-(2,6-dimethylphenylcarbamoylmethyl) triethylammonium chloride (QX314, 1 mM, Tocris); 4-(4-,9-diethoxy-1,3-dihydro-1-oxo-2H-benz[f]isoindol-2-yl)- $N$ (phenylsulfonyl) benzeneacetamide (GW627368X $3 \mu \mathrm{M}$, Tocris); 6-Isopropoxy-9-xanthone-2carboxylic acid (AH6809, $10 \mu \mathrm{M}$, Tocris); $\quad N$-(piperidin-1-yl)-5-(4-iodophenyl)-1-(2,4dichlorophenyl)-4-methyl-1H-pyrazole-3-carboxamide (AM251, $5 \mu \mathrm{M}$, Tocris); Tetrodotoxin (TTX, $0.5 \mu \mathrm{M}$, Tocris); 1,2-bis(2-aminophenoxy)ethane- $N, N, N, N$-tetraacetic acid (BAPTA, $50 \mu \mathrm{M}$, Tocris); and 1,2-Bis(2-aminophenoxy)ethane- $N, N, N, N$-tetra-acetic acid tetrakis (acetoxymethylester) (BAPTA-AM, $20 \mu \mathrm{M})$. All chemicals were from Sigma unless otherwise noted.

\section{Statistical analysis of data}

Statistical significance was evaluated by one-way ANOVA and post hoc Tests (Tukey and Dunn) using Prism software and deemed significant when $\mathrm{P}<0.05$ for the $\left[{ }^{3} \mathrm{H}\right]-\mathrm{AA}$ and $\mathrm{PGE}_{2}$ assay experiments. Normality of the data was evaluated by the Shapiro-Wilk test with $a=0.05$. For electrophysiology experiments, significance was determined by paired or unpaired t-tests or Tukey-Kramer post hoc multiple comparison tests. HPLC/MS/MS lipidomics data were analyzed with ANOVA and Fishers LSD post-hoc test using SPSS when $\mathrm{P}<0.05$ or $\mathrm{P}<0.10$. All results are reported as mean \pm s.e.m.

\section{RESULTS}

\section{$\mathrm{Ca}^{2+}$-independent release of $\left[{ }^{3} \mathrm{H}\right]-\mathrm{AA}$ and its metabolites from cultured astrocytes}

We first assessed the efficiency by which preloading with an inhibitor of the endoplasmic reticulum (ER) $\mathrm{Ca}^{2+}$ pump, cyclopiazonic acid (CPA) $(20 \mu \mathrm{M})$, or the cytosolic $\mathrm{Ca}^{2+}$ chelator $1,2-$ 
bis(o-aminophenoxy) ethane-N,N,N',N'-tetraacetic acid (acetoxymethyl ester) (BAPTA-AM) $(20 \mu \mathrm{M})$ was able to block ATP $(100 \mu \mathrm{M})$ induced cytosolic $\mathrm{Ca}^{2+}$ increases in cultured rat astrocytes. Imaging cytosolic $\mathrm{Ca}^{2+}$ (AAV GFAP cyto-GCaMP6f) showed that the purine agonist ATP $(100 \mu \mathrm{M})$ induced a prompt increase in $\mathrm{Ca}^{2+}$ that was completely blocked in CPA and BAPTA loaded cultures, whereas $10 \mu \mathrm{M}$ methylarachidonyl fluorophosphate (MAFP), a nonspecific inhibitor of both $\mathrm{CPLA}_{2}$ and $\mathrm{PLA}_{2}$, or $10 \mu \mathrm{M}$ of bromoenol lactone (Bel) (Cornell-Bell et al.), a specific inhibitor of $\mathrm{iPLA}_{2}$, did not affect ATP induced $\mathrm{Ca}^{2+}$ rises in astrocytic culture (Figure 1A-C).

As a broad-based approach to AA-specific lipidomics, $\mathrm{Ca}^{2+}$-independent release of $\mathrm{AA}$ and/or its metabolites was performed using a $\left[{ }^{3} \mathrm{H}\right]-\mathrm{AA}$ assay (Figure 2A). Cultured rat astrocytes were pre-incubated overnight with $\left[{ }^{3} \mathrm{H}\right]-\mathrm{AA}$, providing sufficient time for its incorporation into multiple biosynthetic and metabolic pathways. This would include incorporation into membrane phospholipids, which are precursors for endocannabinoids, and related lipids that are themselves precursors for AA release (Chen and Chen, 1998; Strokin et al., 2003). Therefore, this assay serves to determine if any $A A$ precursors or metabolites derived from the $\left[{ }^{3} \mathrm{H}\right]-\mathrm{AA}$ incorporated into the cell are being released; hereafter we refer to the composite of $\left[{ }^{3} \mathrm{H}\right]$-labeled AA metabolites as $\left[{ }^{3} \mathrm{H}\right]-\mathrm{AA}$. ATP alone failed to induce a detectable release of $\left[{ }^{3} \mathrm{H}\right]-\mathrm{AA}$ (Figure 2B); however, in cultures pretreated for 10 to 12 minutes with CPA or BAPTA-AM, ATP evoked a robust increase in the release of $\left[{ }^{3} \mathrm{H}\right]-\mathrm{AA}$, whereas CPA alone had no such effect (Figure 2B). Similarly, we found that upon stimulation with a combination of the non-selective mGluR agonist tACPD $(100 \mu \mathrm{M})$ and the ionotropic glutamate receptor agonist AMPA (100 $\mu \mathrm{M})$, we observed a significant release of $\left[{ }^{3} \mathrm{H}\right]-\mathrm{AA}$ when cytosolic $\mathrm{Ca}^{2+}$ was blocked with $\mathrm{CPA}$, but not in cultures without CPA pretreatment (Figure 2C). These observations confirm that rat astrocytes can release AA derivatives, key precursors of bioactive eicosanoids (Strokin et al., 2003; Rosenegger et al., 2015), but that the AA release is, surprisingly, inhibited by increases in cytosolic $\mathrm{Ca}^{2+}$. 
To explore the mechanism of $\mathrm{Ca}^{2+}$-independent release of $\left[{ }^{3} \mathrm{H}\right]-\mathrm{AA}$, we next evaluated whether inhibition of the $\mathrm{Ca}^{2+}$-sensitive $\mathrm{CPLA}_{2}$ or the $\mathrm{Ca}^{2+}$-insensitive $\mathrm{PLA}_{2}$ enzymes would reduce $\left[{ }^{3} \mathrm{H}\right]-\mathrm{AA}$ release. Pretreatment of astrocytes with $10 \mu \mathrm{M}$ MAFP significantly decreased the ATP-evoked release of $\left[{ }^{3} \mathrm{H}\right]-\mathrm{AA}$ in cultures exposed to CPA (Figure 2D). Similarly, $10 \mu \mathrm{M}$ BEL treatment suppressed the release of $\left[{ }^{3} \mathrm{H}\right]-\mathrm{AA}$, thus confirming a role for $\mathrm{iPLA} \mathrm{A}_{2}$ in $\mathrm{Ca}^{2+}$ independent lipid release (Figure 2D). The $\left[{ }^{3} \mathrm{H}\right]-\mathrm{AA}$ release was only observed when agonistinduced increases in cytosolic $\mathrm{Ca}^{2+}$ were blocked (Figures 2B-C), suggesting that intracellular $\mathrm{Ca}^{2+}$ inhibits the $\mathrm{Ca}^{2+}$-independent $\mathrm{PLA}_{2}$.

Calmodulin is a potent $\mathrm{Ca}^{2+}$-dependent inhibitor of $\mathrm{iPLA}_{2}$ (Wolf and Gross, 1996). To assess the interaction between calmodulin and $\mathrm{PLA}_{2}$, the cells were treated with calmidazolium (CMZ), an inhibitor of $\mathrm{Ca}^{2+} /$ calmodulin interactions that has been shown to remove the calmodulin block of $\mathrm{iPLA}_{2}$ (Wolf and Gross, 1996). In the presence of CMZ $(2 \mu \mathrm{M})$, ATP treatment led to a significant release of $\left[{ }^{3} \mathrm{H}\right]-\mathrm{AA}$, which was comparable to the release upon blocking increases in cytosolic $\mathrm{Ca}^{2+}$ by preloading astrocytes with either CPA or BAPTA (Figure 2D). This observation suggests that $\mathrm{Ca}^{2+}$ acts primarily as a brake through calmodulin, which effectively inhibits iPLA activity (Wolf and Gross, 1996; Wolf et al., 1997). These findings are consistent with previous studies showing that $\mathrm{PLA}_{2}$ is involved in receptor-mediated $\mathrm{AA}$ release from pancreatic islet cells (Gross et al., 1993), smooth muscle cells (Lehman et al., 1993), and endothelial cells (Seegers et al., 2002). Taken together, these data provide evidence of a new signaling mechanism in astrocytes through $\mathrm{Ca}^{2+}$-independent $\mathrm{PLA}_{2}$, which is the major $\mathrm{PLA}_{2}$ isoform in the brain, accounting for $70 \%$ of total PLA 2 activity (Yang et al., 1999).

\section{Targeted lipidomics reveals $\mathrm{Ca}^{2+}$-independent lipid production in cultured astrocytes}

Using lipid extraction and partial purification methods coupled to HPLC/MS/MS, we performed targeted lipidomics screening on cultured astrocytes that were preincubated with CPA and then challenged with ATP, versus vehicle control astrocytes. Of the 50 lipids screened, 30 were present in each of the samples and could thus be used for comparative analyses. 
Figure $3 \mathrm{~A}$ lower panel lists all of the concentrations as mean \pm SEM (Figure 3A). Figure 3A summarizes those lipids showing significant concentration differences, as well as the magnitudes of the differences. Of the 30 lipids detected, 16 (including $A A$ and $P G E_{2}$ ) increased upon ATP challenge in the presence of CPA. Figures 3B-C are representative chromatograms from the HPLC/MS/MS methods used to detect PGE 2 . Notably, 5 of the 8 AA-derivatives in the set were significantly increased by ATP challenge with CPA preincubation, including docosahexaenoyl ethanolamine, although the most dramatic increases were of the prostaglandin, $\mathrm{PGE}_{2}$. Figure 3D shows representative concentration differences in PGE2, DEA, and $A A$.

\section{$\mathrm{Ca}^{2+}$-independent release of $\mathrm{PGE}_{2}$ from cultured astrocytes}

Given that $\mathrm{Ca}^{2+}$-dependent astrocyte lipid release has been previously implicated in vasoregulation (Zonta et al., 2003; Takano et al., 2006; Gordon et al., 2008), it was surprising that $\mathrm{PGE}_{2}$ was released via a $\mathrm{Ca}^{2+}$-independent mechanism. Our HPCL/MS/MS method required large quantities of cells to detect $\mathrm{PGE}_{2}$, whereas the $P G E_{2}$ ELISA assay accurately detects $\mathrm{PGE}_{2}$ release in 24-well cultures. Therefore, we used ELISA to explore and define the $\mathrm{Ca}^{2+}$ dependence of astrocytic $\mathrm{PGE}_{2}$ release. Because $\mathrm{iPLA}_{2}$ is essential for $\mathrm{Ca}^{2+}$-independent liberation of AA-derived lipids, we first assessed whether knockdown of $\mathrm{iPLA}_{2}$ via viral transduction would inhibit astrocytic release of $\mathrm{PGE}_{2}$. In the presence of CPA $(20 \mu \mathrm{M})$, ATP $(100$ $\mu \mathrm{M})$ failed to induce $\mathrm{PGE}_{2}$ release in shRNA-transduced astrocytic cultures, whereas there was a significant increase in the release of $\mathrm{PGE}_{2}$ by ATP in the presence of CPA in control shRNA cultures (Figure 4A). Knockdown of $\mathrm{PLA}_{2}$ via shRNA viral transduction was confirmed with western blot analysis (Figure 4B).

Since cultured astrocytes express mGluR5 (Balazs et al., 1997; Silva et al., 1999; Gebremedhin et al., 2003), we next tested whether the agonists tACPD (100 $\mu$ M) and AMPA $(100 \mu \mathrm{M})$ in the presence/absence of CPA evoked $\mathrm{PGE}_{2}$ release. In the absence of CPA, these agents evoked little to no release of $\mathrm{PGE}_{2}$ (Figure 4C). However, when CPA was used to block 
the release of $\mathrm{Ca}^{2+}$ from internal stores, tACPD and AMPA significantly increased $\mathrm{PGE}_{2}$ release (Figure 4C).

The most abundant mGluR receptors expressed by astrocytes are mGluR5 and mGluR3 (Petralia et al., 1996; Aronica et al., 2000; Tamaru et al., 2001). However, mGluR5 is developmentally regulated and is not expressed by astrocytes in the adult brain, whereas mGluR3 is persistently expressed at high levels throughout adulthood (Sun et al., 2013). It is important to establish whether activation of mGluR3 can induce $\mathrm{Ca}^{2+}$-independent $\mathrm{PGE}_{2}$ release, since activation of this receptor has recently been shown to induce $\mathrm{Ca}^{2+}$ transients in adult hippocampal astrocytes (Haustein et al., 2014; Tang et al., 2015). In the presence of CPA, the mGluR3 agonists NAAG and LY379268 (Wroblewska et al., 1997; Bond et al., 1999) evoked a significant increase in the release of $\mathrm{PGE}_{2}$, whereas the same agonists failed to release $P G E_{2}$ in the absence of CPA (Figure 4D). Notably, this result shows that activation of an astrocytic Gicoupled receptor can release gliotransmitters by a $\mathrm{Ca}^{2+}$-independent mechanism.

To extend the observation to human astrocytes, we performed the same experiments in primary cultured astrocytes harvested from human embryonic tissue (Windrem et al., 2004; Windrem et al., 2008; Han et al., 2013). After pharmacologically assessing iPLA $_{2}$ activity in rat astrocytes (Figure 2D), we evaluated iPLA 2 expression in all the culture models. Western blot analysis showed that $\mathrm{iPLA}_{2}$ expression was not limited to rat astrocytic cultures, but was also expressed in human and mouse astrocytes (Figure 4E). In the presence of CPA, ATP evoked a significant $\mathrm{PGE}_{2}$ release from cultured human astrocytes, whereas little to no release was observed with ATP alone (Figure 4F). Likewise, co-application of tACPD and AMPA showed the same effect (Figure 4F). Taken together, these findings show that ATP or mGluR3 activation leads to $\mathrm{Ca}^{2+}$-independent $\mathrm{PGE}_{2}$ release and that $\mathrm{PLA}_{2}$ is expressed in mouse, rat, and human astrocyte cultures.

\section{$\mathrm{Ca}^{2+}$-independent astrocytic lipid release enhances mEPSPs via Kv channel blockade}


Thus far, experiments have demonstrated that cultured astrocytes in response to agonist exposure can indeed release lipids in a $\mathrm{Ca}^{2+}$-independent pathway. In fact, the in vitro analysis showed that agonist induced $\mathrm{Ca}^{2+}$ increases served to impede $\mathrm{PGE}_{2}$ release, whereas $\mathrm{CPA}$, BAPTA, and CMZ pretreatment potentiated $\mathrm{PGE}_{2}$ release.

Earlier studies have shown that $A A$ and its metabolite $P G E_{2}$ inhibit neuronal $K v$ currents (Horimoto et al., 1997; Nicol et al., 1997; Evans et al., 1999) and thereby enhance excitability (Sekiyama et al., 1995; Chen and Bazan, 2005; Sang et al., 2005). We therefore evaluated whether astrocytic lipid release also inhibits neuronal Kv current and enhances neuronal excitability in acute hippocampal slices. We performed dual patch-clamp recordings of pairs of CA1 pyramidal neurons and astrocytes in acute hippocampal brain slices prepared from 12-18day old mice (Figure 5A). To isolate transiently active potassium currents, we used $100 \mathrm{~ms}$ voltage ramps, which is sufficiently fast to capture transient A-type currents (Phillips et al., 2018). It is worth noting that the I-V ramp enables one to discern what voltage deflection in outward current a drug might affect (Jackson and Bean, 2007). Kv currents in CA1 neurons are an assay for astrocytic lipid release since these currents are sensitive to $A A$ and/or its metabolites (Villarroel and Schwarz, 1996; Carta et al., 2014). We isolated the Kv currents by adding $1 \mathrm{mM} \mathrm{QX314} \mathrm{in} \mathrm{the} \mathrm{patch} \mathrm{pipette} \mathrm{to} \mathrm{block} \mathrm{sodium} \mathrm{channels} \mathrm{(Talbot} \mathrm{and} \mathrm{Sayer,} \mathrm{1996;} \mathrm{Kim}$ et al., 2010) and by imposing a voltage ramp (from $-100 \mathrm{mV}$ to $50 \mathrm{mV}$ ) every 5 seconds to continuously monitor changes in Kv channel current (Ji et al., 2000; Rangroo Thrane et al., 2013b; Carta et al., 2014) as an assay for agonist-induced astrocytic lipid release (Figure 4A). As expected, direct puffing of $\mathrm{PGE}_{2}(50 \mu \mathrm{M})$ or $\mathrm{AA}(50 \mu \mathrm{M})$ from a micropipette significantly reduced the Kv current, in keeping with previous studies (Evans et al., 1999; Carta et al., 2014) (Figure 5B-C).

To assess the effects of astrocytic $\mathrm{Ca}^{2+}$ signaling on neighboring neuronal $\mathrm{Kv}$ channels, we first stimulated astrocytes with ATP or TFLLR- $\mathrm{NH}_{2}$, an agonist of protease-activated receptor-1 (PAR1) that is primarily expressed by astrocytes (Shigetomi et al., 2008). ATP (100 $\mu \mathrm{M})$ induced 
a comparable change in neuronal $\mathrm{Kv}$ when BAPTA $(50 \mu \mathrm{M})$ was present in the astrocyte patch pipette, but not in its absence (Figure 5B-C). A similar transient decrease in Kv current was observed when astrocytes were activated by TFLLR-NH $\mathrm{N}_{2}(30 \mu \mathrm{M})$. Again, the reduction in neuronal Kv currents was only detected when TFLLR was applied, and when BAPTA was added to the astrocytic pipette solution (Fig. 5B-C). To selectively activate astrocytic $\mathrm{Ca}^{2+}$ signaling, we next employed acute hippocampal slices from MrgA1 transgenic animals $\left(\mathrm{MrgA}^{+/-}\right)$, which express the exogenous Gq-coupled MRG receptor (MrgA1) under control of the GFAP promoter. The MrgA1 agonist Phe-Met-Arg-Phe amide (FMRF) mobilizes intracellular astrocytic $\mathrm{Ca}^{2+}$ stores, enabling assessment of the effects of astrocytic $\mathrm{Ca}^{2+}$ signaling on neighboring neuronal Kv currents. Although FMRF $(15 \mu \mathrm{M})$ induces potent and selective increases in astrocytic cytosolic $\mathrm{Ca}^{2+}$ in hippocampal slices (Fiacco et al., 2007; Agulhon et al., 2010; Wang et al., 2012), we saw no detectable changes in neuronal Kv current when the pipette used to patch the astrocyte did not contain BAPTA (Figure 5B-C). However, when BAPTA was present in the astrocyte patch pipette, there was a marked decrease in neuronal Kv current evoked by FMRF exposure (Figure 5B-C). Thus, astrocytes can modulate neuronal Kv current via a previously undocumented $\mathrm{Ca}^{2+}$-independent lipid release.

To assess whether a decrease in neuronal $\mathrm{Kv}$ current is a consequence of $\mathrm{Ca}^{2+}$-independent astrocytic lipid release, we next employed specific lipid receptor antagonists for $\mathrm{PGE}_{2}$ and endocannabinoids. Since $\mathrm{PGE}_{2}$ receptors $1,2,3$, and 4 are expressed on hippocampal pyramidal neurons (Andreasson, 2010; Maingret et al., 2017), we employed AH6809, a PGE 2 EP1, 2, and 3 antagonist (Abramovitz et al., 2000; Ganesh, 2014), and GW627368, a PGE 2 EP4 antagonist (Jones and Chan, 2005; Wilson et al., 2006). With AH6809 (10 $\mu \mathrm{M})$ and GW627368X $(3 \mu \mathrm{M})$ in the perfusion solution, the TFLLR, FMRF, and ATP induced $\mathrm{Ca}^{2+}$ independent $\mathrm{PGE}_{2}$ decrease in neuronal Kv current was abolished (Figure 5C); In contrast, the CB1 antagonist AM251 (5 $\mu \mathrm{M})$ failed to abolish the decrease in Kv current (Figure 5C). Taken 
together, these data suggest that the observed decrease in neuronal Kv current is a result of astrocytic $\mathrm{Ca}^{2+}$-independent release of $\mathrm{PGE}_{2}$.

Interestingly, the presence or absence of BAPTA in the astrocytic pipette solution also affected agonist-induced changes in neuronal membrane potential (Figure 6A). Without BAPTA in astrocyte pipettes, TFLLR induced a hyperpolarization $(-2.4 \pm 0.26 \mathrm{mV})$ (Figure 6A), which has been linked previously to a decrease in extracellular potassium (Wang et al., 2012). However, with BAPTA present in astrocyte pipettes, TFLLR induced depolarization $(2.1 \pm 0.25$ $\mathrm{mV}$ ) (Figure 6A), an effect possibly attributable to the blockage of potassium current.

$\mathrm{PGE}_{2}$ has previously been shown to enhance neuronal mEPSPs (Sekiyama et al., 1995) (Sang et al., 2005). We found that TFLLR-induced activation of astrocytes triggered a decrease in mEPSP amplitude and frequency in normal mouse acute hippocampal slices (Figure 6B). The opposite effect, an increase in the amplitude and frequency of mEPSPs, was observable only when BAPTA was added to the astrocytic pipette solution (Figure $6 \mathrm{C}$ ). This observation supports the notion that astrocytic $\mathrm{Ca}^{2+}$-independent lipid release may function as a signaling mechanism capable of modulating proximal synaptic activity by blocking Kv channels, which in turn may increase the frequency and amplitude of mEPSPs. Interestingly, TFLLR's opposing effects on mEPSP amplitude and frequency were dependent upon astrocytic $\mathrm{Ca}^{2+}$ levels (Figure 6D-E), suggesting that $\mathrm{Ca}^{2+}$ depletion provides a pathway favoring the enhancement by astrocytic $\mathrm{PGE}_{2}$ of neuronal excitability.

\section{DISCUSSION}

Lipidomics has the potential to open exciting new avenues within the field of gliotransmission. In the present study, we utilized a series of lipidomics methodologies to show that $\mathrm{Ca}^{2+}$ chelation followed by metabotropic glutamate or purinergic receptor stimulation provokes the formation of a variety of lipids (Figures 2,3 ) in astrocytes and drives the release of $\mathrm{PGE}_{2}$ in rat 
and human embryonic astrocyte cultures (Figure 4). In addition, we demonstrated that receptormediated $\mathrm{Ca}^{2+}$-independent $\mathrm{PGE}_{2}$ release serves to modulate neuronal $\mathrm{Kv}$ channels, resulting in enhanced synaptic activity in slices detected as increased mEPSP amplitude and frequency (Figures 5, 6). Multiple lines of evidence presented herein also support our hypothesis that this agonist-induced and $\mathrm{Ca}^{2+}$-independent lipid release from astrocytes depends on activation of iPLA . These observations represent, to our knowledge, the first demonstration of $\mathrm{Ca}^{2+}$ independent release of lipid gliotransmitters, and thus add a novel dimension to our understanding of glial-neuronal communication.

Importance of $i P L A_{2}$ pathway in $\mathrm{Ca}^{2+}$-independent astrocytic lipid production

Although astrocytes are known to constitutively release AA and other fatty acids (Moore, 2001; Bouyakdan et al., 2015), the pathways involved in constitutive AA release are currently not known, but inverse agonists of purinergic receptors (Ding et al., 2006) and mGluR (Carroll et al., 2001) might serve as useful pharmacological tools for investigating the constitutive PLA 2 activity in relation to gliotransmission. To date, many studies have shown the multifaceted functions of $\mathrm{PLA}_{2}$ in the CNS, but $\mathrm{PLA}_{2}$ accounts for $70 \%$ of the $\mathrm{PLA}_{2}$ activity in the rat brain (Yang et al., 1999). Although the effects of cPLA 2 activation are best documented (MalaplateArmand et al., 2006; Schaeffer and Gattaz, 2007; Kim et al., 2008), iPLA A $_{2}$ has also been shown to participate in phospholipid remodeling (Sun et al., 2004), and to regulate hippocampal AMPA receptors involved in learning and memory (Menard et al., 2005). Furthermore, iPLA $\mathrm{A}_{2}$ regulates store-operated $\mathrm{Ca}^{2+}$ entry in cerebellar astrocytes (Singaravelu et al., 2006), and provides neuroprotection in an oxygen-glucose deprivation model (Strokin et al., 2006). Astrocytes express both isoforms of $\mathrm{PLA}_{2}$ (Sun et al., 2005), and numerous studies document the release of $\mathrm{AA}$ and its metabolites under regulation of $\mathrm{Ca}^{2+}$-dependent $\mathrm{PLA}_{2} \quad\left(\mathrm{CPLA}_{2}\right)$ signaling in astrocytes (Bruner and Murphy, 1990; Stella et al., 1994; Stella et al., 1997; Chen and Chen, 1998). Previous studies have demonstrated astrocytic release of DHA via iPLA2 (Strokin et al., 2003, 2007). Here, we focused on the largely unexplored iPLA 2 lipid pathway mediating PGE2 
release from astrocytes. Given the ubiquitous expression of $\mathrm{iPLA}_{2}$ in astrocytes throughout the brain, we contend that various receptor-activated pathways converge on $\mathrm{iPLA}$ for the regulation of astrocyte lipid release (Figure 7).

$\mathrm{Ca}^{2+}$-independent astrocytic $P G E_{2}$ release for rapid modulation of neuronal Kv channels

An important aspect of astrocytic gliotransmitter release is its timing. Agonist-induced astrocytic $\mathrm{Ca}^{2+}$ increases occur on a slow time scale of seconds (Cornell-Bell et al., 1990; Wang et al., 2006; Srinivasan et al., 2015), which allows integration of many factors on that time scale. Increased intracellular $\mathrm{Ca}^{2+}$ is a key step in the release of gliotransmitters (Parpura et al., 1994; Bezzi et al., 1998; Kang et al., 1998), such as ATP (Coco et al., 2003; Parpura and Zorec, 2010; Illes et al., 2019) and D-Serine (Mothet et al., 2000; Yang et al., 2003; Li et al., 2018; Neame et al., 2019). We have recently shown that agonist-induced astrocytic $\mathrm{Ca}^{2+}$ signaling can modulate synaptic activity by promoting $\mathrm{K}^{+}$uptake, resulting in a transient lowering of extracellular $\mathrm{K}^{+}$and depression of synaptic activity (Wang et al., 2012). More recently, we demonstrated that astrocytes can modulate a rapid form of synaptic activity ( $\geq 500 \mathrm{~ms}$ ) via 2AG release upon agonism of mGluR3 receptors (Smith et al., 2019). Because receptor-mediated astrocytic $\mathrm{Ca}^{2+}$ drives $\mathrm{K}^{+}$uptake and release of gliotransmitters, these processes must, therefore, occur over a relatively prolonged time course (>500 ms). However, agonist-induced $\mathrm{Ca}^{2+}$-independent iPLA lipid release does not require the mobilization of intracellular $\mathrm{Ca}^{2+}$ stores, thus imparting the potential to signal on a much faster time scale, possibly within 10 s of milliseconds. We

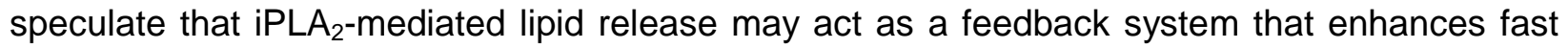
synaptic transmission in the short-term or under conditions of minimal neuronal activity, whereas subsequent activity-mediated increases in $\mathrm{Ca}^{2+}$ serve as a brake in the form of the calmodulindependent inhibition of $\mathrm{iPLA}_{2}$. The slower $\mathrm{Ca}^{2+}$-dependent release of gliotransmitters and stimulation of $\mathrm{K}^{+}$uptake seems more suited toward the slow and widespread modulation of 
brain activity (typically inhibition) that occurs in the setting of, for example, tonic activation of the locus coeruleus and consequent norepinephrine release (Bekar et al., 2008; Ding et al., 2013).

Voltage-gated potassium channels are located on the dendrites of hippocampal pyramidal neurons (Johnston et al., 2000), where they play a major role in controlling dendritic excitability by modulating the amplitude of EPSPs. A morphological study found that the density of Kv channels in the dendrites of pyramidal neurons increased 5-fold proceeding from the soma to the most distal point measured in the apical dendrites (Hoffman et al., 1997). Inhibition of voltage-gated $\mathrm{K}^{+}$currents will consequently enhance EPSPS, possibly explaining why $\mathrm{PGE}_{2}$ enhances synaptic transmission and LTP in the hippocampus (Sang et al., 2005).

\section{Lipidomics models as a guide for future gliotransmitter discoveries}

Lipidomics is one of the fastest-growing branches of the metabolomics field, and offers the possibility of describing the enormous diversity of lipid species throughout the body, and especially in the brain, which is largely composed of lipids (Sinclair, 1975). The complex and fine structure of astrocytic processes gives astrocytes a larger surface area to volume ratio than most other cell types, which makes them uniquely responsive to changes in the extracellular milieu. HPLC/MS/MS lipidomics techniques have provided a means to quantify specific lipid species with an accuracy and sensitivity not possible with more traditional methods employing radio-labeled fatty acids and ELISA. Here, we have combined these classical techniques with lipidomics to test the hypothesis that lipids are produced and released from astrocytes in a $\mathrm{Ca}^{2+}$ independent manner. Although our present focus was on the release of $\mathrm{PGE}_{2}$, we found upregulated release of 15 additional lipids. Notably, among the 30 lipids measured in the present targeted HPLC/MS/MS assay, 14 did not change upon activation of glial receptors, supporting the specificity of GPCR stimulated, $\mathrm{Ca}^{2+}$-independent lipid release. Interestingly, two of the lipids released in response to agonist exposure, namely $N$-arachidonyl taurine and $N$-palmitoyl tyrosine, were recently shown to activate TRPV4, a cation channel involved in osmotic 
sensitivity and mechanosensitivity (Raboune et al., 2014). Emerging evidence suggests that a TRPV4/AQP4 complex regulates the response to hypo-osmotic stress in astrocytes (Benfenati et al., 2011). The present lipidomics data thus casts light on unpredicted signaling mechanisms that involve astrocytic-derived lipid modulators (Figure 3).

\section{Potential physiological relevance of calcium-independent lipid release}

Astrocytes are now known to respond to single experimental stimulation events with small calcium increases in their distal fine processes (Panatier et al., 2011). This results from synchronous firing of as many as 50-1000 synapses in the astrocytes microdomain, as may occur when a large stimulation is applied as far as $500 \mu \mathrm{m}$ away. However, the spontaneous activity of asynchronous synaptic events need not elicit astrocyte calcium events. Metabotropic GluR- and AMPA-mediated activation of astrocytes may elicit $\mathrm{PLA}_{2}$ activation and the concerted liberation of $\mathrm{AA}$ metabolites and $\mathrm{PGE}_{2}$ to affect pre- and post-synaptic potassium channels on nearby neurons. When stimulation frequency and/or amplitude increase, astrocytic calcium rises would then serve to suppress over-activation of synapses. In this way, astrocytes may help maintain the strength of relatively quiescent synapses in a calcium-independent fashion, while employing multiple calcium-dependent mechanisms to suppress over-activation. Substantiation of this model requires rigorous testing of the spatial and temporal dynamics of astrocytic and individual dendritic activation, but are limited by current methodological capabilities that do not allow electrical recording of individual dendritic spines.

In conclusion, $\mathrm{Ca}^{2+}$-independent astrocytic lipid release constitutes a largely unexplored factor in the regulation of complex neuro-glial signaling interactions. Our present analysis adds a new dimension to the understanding of agonist-induced $\mathrm{Ca}^{2+}$ signaling by demonstrating that agonism of several $\mathrm{Gq}$ and Gi-linked astrocytic receptors can promote the release of lipid modulators, and that increases in cytosolic $\mathrm{Ca}^{2+}$ act as a brake to prevent $\mathrm{PGE}_{2}$ release. 
Author contributions: F.W., H.B.B., and N.A.S. performed the experiments. F.W., H.B.B., J.X., and N.A.S. analyzed data. S.P. and B.J. performed Western Blots. S.G. and B.L. made cultures. L.B. and N.A.S. planned the experiments. D.C.M. provided Human Astrocytes. F.W., H.B.B., and N.A.S. wrote the paper.

Acknowledgments: We thank Dr. Ken McCarthy for generously sharing transgenic mice. This work was supported by the National Institutes of Health Grant K01NS110981, NSFNCS-FR 1926781, and Department of Defense Army Research Office Award W91NF2020189 to N.A.S. We thank Vittorio Gallo, Baljit Khakh, Bartosz Kula, Stefano Vicini, Alexander S. Thrane, Vinita Rangroo Thrane, Takahiro Takano, Paul Cumming, and Fernando R. Fernandez for comments and critical discussion for this manuscript. The authors declare no competing financial interest. 


\section{Figure Legends}

Figure 1: GPCR-evoked $\mathrm{Ca}^{2+}$ transients in astrocytic cultures.

A.) Cultured astrocytes were transduced with AAV GFAP cyto-GCaMP6f and the fluorescent changes associated with intracellular $\mathrm{Ca}^{2+}$ increases upon ATP stimulation were measured using confocal microscopy. B.) Representative individual traces of GCaMP6f fluorescence changes $\left(\Delta \mathrm{F} / \mathrm{F}_{0}\right)$ in response to ATP stimulation (upper panel). C.) BAPTA-AM $(20 \mu \mathrm{M}, \mathrm{n}=5$ wells) and CPA $(20 \mu \mathrm{M}, \mathrm{n}=5$ wells $)$ eliminated the ATP $(100 \mu \mathrm{M}, \mathrm{n}=5$ wells $)$ evoked $\mathrm{Ca}^{2+}$ increases in fluorescent. MAFP $(10 \mu \mathrm{M}, \mathrm{n}=5$ wells $)$, Bel $(10 \mu \mathrm{M}, \mathrm{n}=5$ wells $)$ did not inhibit ATP $(100 \mu \mathrm{M})$ induced $\mathrm{Ca}^{2+}$ rises in Astrocytes. ${ }^{* * *} \mathrm{P} \leq 0.0001$, Tukey's post-hoc test. All bar graphs show means \pm s.e.m.

Figure 2: GPCR-mediated $\mathrm{Ca}^{2+}$ independent release of ${ }^{3} \mathrm{H}-\mathrm{AA}$ and/ or its metabolites from astrocytic cultures.

A.) Schematic of the ${ }^{3} \mathrm{H}$-AA Radioactive Assay. B.) The effects of ATP (100 $\mu \mathrm{M}, \mathrm{n}=45$ wells), CPA (20 $\mu M, n=9$ wells), ATP/CPA ( $n=44$ wells), and ATP/BAPTA-AM ( $n=24$ wells) on $\mathrm{Ca}^{2+}$ independent release of $\left[{ }^{3} \mathrm{H}\right]-\mathrm{AA}$ and its derivatives in astrocytic cultures compared to control and each other. ${ }^{* *} \mathrm{P} \leq 0.0001 ;{ }^{*} \mathrm{P} \leq 0.001 ;{ }^{*} \mathrm{P} \leq 0.05$, Tukey's post-hoc test. C.) The effects of mGluR agonists tACPD/AMPA (100 $\mu M, n=7)$, tACPD/AMPA/CPA ( $n=7$ wells), and ATP/CPA ( $n=7$ wells) on $\mathrm{Ca}^{2+}$-independent release of $\left[{ }^{3} \mathrm{H}\right]-\mathrm{AA}$ and its derivatives in astrocytic cultures compared to control and individual effects. ${ }^{* *} \mathrm{P} \leq 0.0001 ;{ }^{* *} \mathrm{P} \leq 0.001 ;{ }^{*} \mathrm{P} \leq 0.05$, Tukey's post-hoc test. D.) Effects of the iPLA $A_{2}$ inhibitor, BEL $(10 \mu \mathrm{M}, \mathrm{n}=12$ wells $), \mathrm{cPLA}_{2}$ inhibitor, MAFP $(10 \mu \mathrm{M}, \mathrm{n}=12$ wells), or Calmodulin/ $\mathrm{Ca}^{2+}$ complex inhibitor, $\mathrm{CMZ}(2 \mu \mathrm{M}, \mathrm{n}=20$ wells $)$ co-applied with ATP on $\mathrm{Ca}^{2+}$ independent release of $\left[{ }^{3} \mathrm{H}\right]-\mathrm{AA}$ and its derivatives in astrocytic cultures compared to ATP alone. ${ }^{* *} \mathrm{P} \leq 0.0001 ;{ }^{* *} \mathrm{P} \leq 0.001$, Tukey's post-hoc test. All bar graphs show means \pm s.e.m.

Figure 3. Targeted lipidomics of rat astrocytic cultures using HPLC/MS/MS. 
A.) Summary of the significant differences and the magnitude of change between the vehicle controls and the CPA/ATP stimulated cells for the 30 lipids in the screen that were detected across samples. Dark green denotes significant differences ( $p \leq 0.05)$; light green denotes trending increases $(0.10 \geq p \leq 0.05)$. No significant difference is signified by "n.d.". Arrows indicate the magnitude of effects, as indicated in the legend. Raw data and statistical analyses for all lipids detected are shown in figure table. B.) Example chromatograph of a PGE2 standard (1 pmol) as analyzed by the HPLC/MS/MS method optimized for this standard in negative ion mode. C.) Example of an analysis of a partially purified astrocytic extract using the HPLC/MS/MS method that is optimized for PGE2. D.) Differences in astrocytic production of AA and two of its derivatives, PGE2 and docosahexaenoyl ethanolamine (DEA), expressed as the average moles/sample; vehicle $n=3$ flask, CPA/ATP $n=4$ flask.

\section{Figure 4: GPCR-mediated $\mathrm{Ca}^{2+}$ independent release of $\mathrm{PGE}_{2}$ from astrocytic cultures.}

A.) The effects of ATP $\left(100 \mu \mathrm{M}, \mathrm{n}=4\right.$ wells) and ATP/CPA ( $n=4$ wells) on $\mathrm{Ca}^{2+}$ independent PGE 2 release in rat astrocytic cultures virally transduced with shRNA to knockdown $\mathrm{iPLA}_{2}$ comparted to control shRNA cultures. ${ }^{*} \mathrm{P} \leq 0.05$, Dunn post-test. B.) Western blot analysis of $\mathrm{iPLA}_{2}$ knockdown via shRNA. $\beta$-actin specific antibody was used to standardize for equal protein loading. C.) The effects of GPCR agonists ATP (100 $\mu \mathrm{M}, \mathrm{n}=12$ wells), tACPD/AMPA (100 $\mu \mathrm{M}$, $\mathrm{n}=7$ wells), tACPD/AMPA/CPA $(\mathrm{n}=7)$, and ATP/CPA ( $\mathrm{n}=12$ wells) on $\mathrm{Ca}^{2+}$-independent PGE 2 release in rat astrocytic cultures compared to control. ${ }^{* * *} \mathrm{P} \leq 0.0001 ;{ }^{* *} \mathrm{P} \leq 0.001$, Tukey's posttest. D.) The effects of ATP/CPA (100uM, $n=4)$ and mGluR3 agonist NAAG (100 $\mu \mathrm{M}, \mathrm{n}=4$ wells), LY379268 (100 $\mu \mathrm{M}, \mathrm{n}=4$ wells), NAAG/CPA ( $\mathrm{n}=4)$, and LY379268/CPA ( $\mathrm{n}=4$ wells) on $\mathrm{Ca}^{2+}$ independent $\mathrm{PGE}_{2}$ release in rat astrocytic cultures compared to control and each other. ${ }^{* * *} \mathrm{P} \leq 0.001$, Tukey's post-test. E.) Western blot analysis of $\mathrm{PLA}_{2}$ protein for human, rat, and mouse cultures. $\beta$-actin specific antibody was used to standardize for equal protein loading. F.) The effects of GPCR agonists ATP (100 $\mu \mathrm{M}, \mathrm{n}=8$ wells), ATP/CPA ( $\mathrm{n}=8$ wells), tACPD/AMPA (100 $\mu \mathrm{M}, \mathrm{n}=8$ wells), and tACPD/AMPA/CPA ( $\mathrm{n}=8$ wells) on $\mathrm{Ca}^{2+}$-independent $\mathrm{PGE}_{2}$ release in 
human astrocytic cultures compared to control and each other. ${ }^{* *} \mathrm{P} \leq 0.0001 ;{ }^{* *} \mathrm{P} \leq 0.001$; ${ }^{*} \mathrm{P} \leq 0.05$, Tukey's post-hoc test. All bar graphs show means \pm s.e.m.

\section{Figure 5: $\mathrm{Ca}^{2+}$-independent astrocytic lipid release inhibits $\mathrm{Kv}$ channel blockade.}

A.) Image of a patched astrocyte and a patched neuron, filled with fluorescent dyes. B.) Direct application of AA $(50 \mu \mathrm{M})$ and PGE2 $(50 \mu \mathrm{M})$ decreased Kv current. ATP $(100 \mu \mathrm{M})$ and TFLLR $(30 \mu \mathrm{M})$ together with BAPTA also decreased Kv current, as can be seen in the peak currents. FMRF $(15 \mu \mathrm{M})$ in the $\mathrm{MrgA} 1^{+/-}$mice applied in the presence of BAPTA decreased Kv current, but not in the absence of BAPTA. Traces to the left are representative recordings of changes to membrane voltages in the presence of drugs described above. C.) Quantitation of effects of different drugs on the holding voltage ramp induced voltage gated $\mathrm{K}^{+}$currents $\left({ }^{*}, \mathrm{p}<0.05,{ }^{* *}, \mathrm{p}\right.$ $<0.01, \mathrm{n}=5-7$ mice). All bar graphs show mean \pm s.e.m.

Figure 6: $\mathrm{Ca}^{2+}$-independent astrocytic lipid release increase mEPSP amplitude and frequency.

A.) Representative traces showing changes to membrane potentials VM upon TFLLR application in the presence or absence of BAPTA, and quantitations are shown in inset $\left({ }^{* *}, \mathrm{p}<\right.$ 0.01, t-test, $n=5-6$ mice). B.) Representative trace showing hyperpolarization and reduction in mEPSP amplitude and frequency in excitatory hippocampal neurons upon TFLLR $(30 \mu \mathrm{M})$ application without BAPTA being present in neighboring astrocytes. C.) Representative trace showing depolarization and an increase in mEPSP amplitude and frequency in excitatory hippocampal neurons upon TFLLR $(30 \mu \mathrm{M})$ application with BAPTA present in neighboring astrocytes. Lower traces are extensions of parts of recordings in upper trace. D.) Comparison of the cumulative mEPSP amplitude and cumulative mEPSP frequency distribution recorded in B). E.) Statistical analysis of the amplitude and inter-event intervals before and after TFLLR application, with and without BAPTA present $\left({ }^{* *}, \mathrm{p}<001\right.$, paired t-test, $\mathrm{N}=5-7$ mice). All bar graphs show mean \pm s.e.m. 
Figure 7: Models of GPCR-mediated $\mathrm{Ca}^{2+}$-independent and $\mathrm{Ca}^{2+}$-dependent lipid release in astrocytes.

A.) Schematic of receptor mediated $\mathrm{Ca}^{2+}$-Independent lipid release across the astrocytic membrane. B.) Schematic of receptor mediated $\mathrm{Ca}^{2+}$-Dependent lipid release across the astrocytic membrane. 


\section{References}

Abramovitz M, Adam M, Boie Y, Carriere M, Denis D, Godbout C, Lamontagne S, Rochette C, Sawyer N, Tremblay NM, Belley M, Gallant M, Dufresne C, Gareau Y, Ruel R, Juteau H, Labelle M, Ouimet N, Metters KM (2000) The utilization of recombinant prostanoid receptors to determine the affinities and selectivities of prostaglandins and related analogs. Biochim Biophys Acta 1483:285-293.

Agulhon C, Fiacco TA, McCarthy KD (2010) Hippocampal short- and long-term plasticity are not modulated by astrocyte Ca2+ signaling. Science 327:1250-1254.

Akiba S, Hayama M, Sato T (1998) Inhibition of Ca2+-independent phospholipase A2 by bromoenol lactone attenuates prostaglandin generation induced by interleukin-1 beta and dibutyryl cAMP in rat mesangial cells. FEBS Lett 437:225-228.

Andreasson K (2010) Emerging roles of PGE2 receptors in models of neurological disease. Prostaglandins Other Lipid Mediat 91:104-112.

Aronica E, van Vliet EA, Mayboroda OA, Troost D, da Silva FH, Gorter JA (2000) Upregulation of metabotropic glutamate receptor subtype mGluR3 and mGluR5 in reactive astrocytes in a rat model of mesial temporal lobe epilepsy. The European journal of neuroscience 12:2333-2344.

Balazs R, Miller S, Romano C, de Vries A, Chun Y, Cotman CW (1997) Metabotropic glutamate receptor mGluR5 in astrocytes: pharmacological properties and agonist regulation. $\mathrm{J}$ Neurochem 69:151-163.

Bekar LK, He W, Nedergaard M (2008) Locus coeruleus alpha-adrenergic-mediated activation of cortical astrocytes in vivo. Cerebral cortex 18:2789-2795.

Benfenati V, Caprini M, Dovizio M, Mylonakou MN, Ferroni S, Ottersen OP, AmiryMoghaddam M (2011) An aquaporin-4/transient receptor potential vanilloid 4 (AQP4/TRPV4) complex is essential for cell-volume control in astrocytes. Proc Natl Acad Sci U S A 108:2563-2568.

Bezzi P, Carmignoto G, Pasti L, Vesce S, Rossi D, Rizzini BL, Pozzan T, Volterra A (1998) Prostaglandins stimulate calcium-dependent glutamate release in astrocytes. Nature 391:281-285.

Boland LM, Drzewiecki MM (2008) Polyunsaturated fatty acid modulation of voltage-gated ion channels. Cell biochemistry and biophysics 52:59-84.

Bond A, Ragumoorthy N, Monn JA, Hicks CA, Ward MA, Lodge D, O'Neill MJ (1999) LY379268, a potent and selective Group II metabotropic glutamate receptor agonist, is neuroprotective in gerbil global, but not focal, cerebral ischaemia. Neurosci Lett 273:191194.

Bouyakdan K, Taib B, Budry L, Zhao S, Rodaros D, Neess D, Mandrup S, Faergeman NJ, Alquier T (2015) A novel role for central ACBP/DBI as a regulator of long-chain fatty acid metabolism in astrocytes. J Neurochem 133:253-265.

Bruner G, Murphy S (1990) ATP-evoked arachidonic acid mobilization in astrocytes is via a P2Y-purinergic receptor. J Neurochem 55:1569-1575.

Carroll FY, Stolle A, Beart PM, Voerste A, Brabet I, Mauler F, Joly C, Antonicek H, Bockaert J, Muller T, Pin JP, Prezeau L (2001) BAY36-7620: a potent non-competitive mGlu1 receptor antagonist with inverse agonist activity. Mol Pharmacol 59:965-973.

Carta M, Lanore F, Rebola N, Szabo Z, Da Silva SV, Lourenco J, Verraes A, Nadler A, Schultz C, Blanchet C, Mulle C (2014) Membrane Lipids Tune Synaptic Transmission by Direct Modulation of Presynaptic Potassium Channels. Neuron. 
Chen C, Bazan NG (2005) Endogenous PGE2 regulates membrane excitability and synaptic transmission in hippocampal CA1 pyramidal neurons. J Neurophysiol 93:929-941.

Chen WC, Chen CC (1998) ATP-induced arachidonic acid release in cultured astrocytes is mediated by Gi protein coupled P2Y1 and P2Y2 receptors. Glia 22:360-370.

Coco S, Calegari F, Pravettoni E, Pozzi D, Taverna E, Rosa P, Matteoli M, Verderio C (2003) Storage and release of ATP from astrocytes in culture. J Biol Chem 278:1354-1362.

Cordero-Morales JF, Vasquez V (2018) How lipids contribute to ion channel function, a fat perspective on direct and indirect interactions. Curr Opin Struct Biol 51:92-98.

Cornell-Bell AH, Finkbeiner SM, Cooper MS, Smith SJ (1990) Glutamate induces calcium waves in cultured astrocytes: long-range glial signaling. Science 247:470-473.

Czigler A, Toth L, Szarka N, Szilagyi K, Kellermayer Z, Harci A, Vecsernyes M, Ungvari Z, Szolics A, Koller A, Buki A, Toth P (2019) Prostaglandin E2, a postulated mediator of neurovascular coupling, at low concentrations dilates whereas at higher concentrations constricts human cerebral parenchymal arterioles. Prostaglandins Other Lipid Mediat 146:106389.

Dabertrand F, Hannah RM, Pearson JM, Hill-Eubanks DC, Brayden JE, Nelson MT (2013) Prostaglandin E2, a postulated astrocyte-derived neurovascular coupling agent, constricts rather than dilates parenchymal arterioles. J Cereb Blood Flow Metab 33:479-482.

Dhopeshwarkar GA, Subramanian C (1976) Biosynthesis of polyunsaturated fatty acids in the developing brain: I. Metabolic transformations of intracranially administered 1-14C linolenic acid. Lipids 11:67-71.

Ding F, O'Donnell J, Thrane AS, Zeppenfeld D, Kang H, Xie L, Wang F, Nedergaard M (2013) alpha1-Adrenergic receptors mediate coordinated $\mathrm{Ca} 2+$ signaling of cortical astrocytes in awake, behaving mice. Cell calcium 54:387-394.

Ding Z, Kim S, Kunapuli SP (2006) Identification of a potent inverse agonist at a constitutively active mutant of human P2Y12 receptor. Mol Pharmacol 69:338-345.

Evans AR, Vasko MR, Nicol GD (1999) The cAMP transduction cascade mediates the PGE2induced inhibition of potassium currents in rat sensory neurones. J Physiol 516 ( $\mathrm{Pt}$ 1):163-178.

Fiacco TA, Agulhon C, Taves SR, Petravicz J, Casper KB, Dong X, Chen J, McCarthy KD (2007) Selective stimulation of astrocyte calcium in situ does not affect neuronal excitatory synaptic activity. Neuron 54:611-626.

Ganesh T (2014) Prostanoid receptor EP2 as a therapeutic target. J Med Chem 57:4454-4465.

Gebremedhin D, Yamaura K, Zhang C, Bylund J, Koehler RC, Harder DR (2003) Metabotropic glutamate receptor activation enhances the activities of two types of $\mathrm{Ca} 2+$-activated $\mathrm{k}+$ channels in rat hippocampal astrocytes. The Journal of neuroscience : the official journal of the Society for Neuroscience 23:1678-1687.

Gordon GR, Mulligan SJ, MacVicar BA (2007) Astrocyte control of the cerebrovasculature. Glia 55:1214-1221.

Gordon GR, Choi HB, Rungta RL, Ellis-Davies GC, MacVicar BA (2008) Brain metabolism dictates the polarity of astrocyte control over arterioles. Nature 456:745-749.

Gross RW, Ramanadham S, Kruszka KK, Han X, Turk J (1993) Rat and human pancreatic islet cells contain a calcium ion independent phospholipase A2 activity selective for hydrolysis of arachidonate which is stimulated by adenosine triphosphate and is specifically localized to islet beta-cells. Biochemistry 32:327-336. 
Han X, Chen M, Wang F, Windrem M, Wang S, Shanz S, Xu Q, Oberheim NA, Bekar L, Betstadt S, Silva AJ, Takano T, Goldman SA, Nedergaard M (2013) Forebrain engraftment by human glial progenitor cells enhances synaptic plasticity and learning in adult mice. Cell Stem Cell 12:342-353.

Haustein MD, Kracun S, Lu XH, Shih T, Jackson-Weaver O, Tong X, Xu J, Yang XW, O'Dell TJ, Marvin JS, Ellisman MH, Bushong EA, Looger LL, Khakh BS (2014) Conditions and constraints for astrocyte calcium signaling in the hippocampal mossy fiber pathway. Neuron 82:413-429.

Hoffman DA, Magee JC, Colbert CM, Johnston D (1997) K+ channel regulation of signal propagation in dendrites of hippocampal pyramidal neurons. Nature 387:869-875.

Horimoto N, Nabekura J, Ogawa T (1997) Arachidonic acid activation of potassium channels in rat visual cortex neurons. Neuroscience 77:661-671.

Illes P, Burnstock G, Tang Y (2019) Astroglia-Derived ATP Modulates CNS Neuronal Circuits. Trends in neurosciences 42:885-898.

Jackson AC, Bean BP (2007) State-dependent enhancement of subthreshold A-type potassium current by 4-aminopyridine in tuberomammillary nucleus neurons. The Journal of neuroscience : the official journal of the Society for Neuroscience 27:10785-10796.

Jelsema CL, Axelrod J (1987) Stimulation of phospholipase A2 activity in bovine rod outer segments by the beta gamma subunits of transducin and its inhibition by the alpha subunit. Proc Natl Acad Sci U S A 84:3623-3627.

Ji J, Salapatek AM, Diamant NE (2000) Inwardly rectifying K(+) channels in esophageal smooth muscle. Am J Physiol Gastrointest Liver Physiol 279:G951-960.

Johnston D, Hoffman DA, Magee JC, Poolos NP, Watanabe S, Colbert CM, Migliore M (2000) Dendritic potassium channels in hippocampal pyramidal neurons. J Physiol 525 Pt 1:7581.

Jones RL, Chan KM (2005) Investigation of the agonist activity of prostacyclin analogues on prostanoid EP4 receptors using GW 627368 and taprostene: evidence for species differences. Prostaglandins Leukot Essent Fatty Acids 72:289-299.

Kang J, Jiang L, Goldman SA, Nedergaard M (1998) Astrocyte-mediated potentiation of inhibitory synaptic transmission. Nature neuroscience 1:683-692.

Kim DH, Fitzsimmons B, Hefferan MP, Svensson CI, Wancewicz E, Monia BP, Hung G, Butler M, Marsala M, Hua XY, Yaksh TL (2008) Inhibition of spinal cytosolic phospholipase $\mathrm{A}(2)$ expression by an antisense oligonucleotide attenuates tissue injury-induced hyperalgesia. Neuroscience 154:1077-1087.

Kim JH, Kushmerick C, von Gersdorff H (2010) Presynaptic resurgent Na+ currents sculpt the action potential waveform and increase firing reliability at a CNS nerve terminal. The Journal of neuroscience : the official journal of the Society for Neuroscience 30:1547915490.

Ledo A, Rocha BS, Laranjinha J (2019) Bioactive Lipids and the Gut-Brain Axis: Diet as a Modulator of Bioactivity and Diversity of Lipids in the Brain. Adv Exp Med Biol 1127:147-168.

Lehman JJ, Brown KA, Ramanadham S, Turk J, Gross RW (1993) Arachidonic acid release from aortic smooth muscle cells induced by [Arg8]vasopressin is largely mediated by calcium-independent phospholipase A2. J Biol Chem 268:20713-20716.

Leishman E, Manchanda M, Thelen R, Miller S, Mackie K, Bradshaw HB (2018) Cannabidiol's Upregulation of N-acyl Ethanolamines in the Central Nervous System Requires N-acyl 
Phosphatidyl Ethanolamine-Specific Phospholipase D. Cannabis Cannabinoid Res 3:228241.

Li S, Uno Y, Rudolph U, Cobb J, Liu J, Anderson T, Levy D, Balu DT, Coyle JT (2018) Astrocytes in primary cultures express serine racemase, synthesize d-serine and acquire A1 reactive astrocyte features. Biochem Pharmacol 151:245-251.

Lin JH, Weigel H, Cotrina ML, Liu S, Bueno E, Hansen AJ, Hansen TW, Goldman S, Nedergaard M (1998) Gap-junction-mediated propagation and amplification of cell injury. Nat Neurosci 1:494-500.

MacVicar BA, Newman EA (2015) Astrocyte regulation of blood flow in the brain. Cold Spring Harb Perspect Biol 7.

Maingret V, Barthet G, Deforges S, Jiang N, Mulle C, Amedee T (2017) PGE2-EP3 signaling pathway impairs hippocampal presynaptic long-term plasticity in a mouse model of Alzheimer's disease. Neurobiol Aging 50:13-24.

Malaplate-Armand C, Florent-Bechard S, Youssef I, Koziel V, Sponne I, Kriem B, LeiningerMuller B, Olivier JL, Oster T, Pillot T (2006) Soluble oligomers of amyloid-beta peptide induce neuronal apoptosis by activating a cPLA2-dependent sphingomyelinase-ceramide pathway. Neurobiol Dis 23:178-189.

Menard C, Valastro B, Martel MA, Chartier E, Marineau A, Baudry M, Massicotte G (2005) AMPA receptor phosphorylation is selectively regulated by constitutive phospholipase A(2) and 5-lipoxygenase activities. Hippocampus 15:370-380.

Meves H (1994) Modulation of ion channels by arachidonic acid. Prog Neurobiol 43:175-186.

Moore SA (1993) Cerebral endothelium and astrocytes cooperate in supplying docosahexaenoic acid to neurons. Adv Exp Med Biol 331:229-233.

Moore SA (2001) Polyunsaturated fatty acid synthesis and release by brain-derived cells in vitro. J Mol Neurosci 16:195-200; discussion 215-121.

Moore SA, Yoder E, Murphy S, Dutton GR, Spector AA (1991) Astrocytes, not neurons, produce docosahexaenoic acid (22:6 omega-3) and arachidonic acid (20:4 omega-6). J Neurochem 56:518-524.

Mothet J, Parent A, Wolosker H, Jr RB, Linden D, Ferris C, Rogawski M, Synder S (2000) Dserine is an endogenous ligand for the site of N-methyl D-aspartate receptor. Proc Natl Acad Sci U S A 97:4926-4931.

Murayama T, Kajiyama Y, Nomura Y (1990) Histamine-stimulated and GTP-binding proteinsmediated phospholipase A2 activation in rabbit platelets. J Biol Chem 265:4290-4295.

Neame S, Safory H, Radzishevsky I, Touitou A, Marchesani F, Marchetti M, Kellner S, Berlin S, Foltyn VN, Engelender S, Billard JM, Wolosker H (2019) The NMDA receptor activation by d-serine and glycine is controlled by an astrocytic Phgdh-dependent serine shuttle. Proceedings of the National Academy of Sciences of the United States of America 116:20736-20742.

Nedergaard M (1994) Direct signaling from astrocytes to neurons in cultures of mammalian brain cells. Science 263:1768-1771.

Nicol GD, Vasko MR, Evans AR (1997) Prostaglandins suppress an outward potassium current in embryonic rat sensory neurons. J Neurophysiol 77:167-176.

Panatier A, Vallee J, Haber M, Murai KK, Lacaille JC, Robitaille R (2011) Astrocytes are endogenous regulators of basal transmission at central synapses. Cell 146:785-798.

Parpura V, Zorec R (2010) Gliotransmission: Exocytotic release from astrocytes. Brain Res Rev 63:83-92. 
Parpura V, Basarsky TA, Liu F, Jeftinija K, Jeftinija S, Haydon PG (1994) Glutamate-mediated astrocyte-neuron signalling. Nature 369:744-747.

Petralia RS, Wang YX, Niedzielski AS, Wenthold RJ (1996) The metabotropic glutamate receptors, mGluR2 and mGluR3, show unique postsynaptic, presynaptic and glial localizations. Neuroscience 71:949-976.

Phillips WS, Del Negro CA, Rekling JC (2018) Dendritic A-Current in Rhythmically Active PreBotzinger Complex Neurons in Organotypic Cultures from Newborn Mice. The Journal of neuroscience : the official journal of the Society for Neuroscience 38:30393049.

Piomelli D (1993) Arachidonic acid in cell signaling. Current opinion in cell biology 5:274-280.

Plog BA, Nedergaard M (2018) The Glymphatic System in Central Nervous System Health and Disease: Past, Present, and Future. Annu Rev Pathol 13:379-394.

Portilla D, Shah SV, Lehman PA, Creer MH (1994) Role of cytosolic calcium-independent plasmalogen-selective phospholipase A2 in hypoxic injury to rabbit proximal tubules. The Journal of clinical investigation 93:1609-1615.

Ramakers GM, Storm JF (2002) A postsynaptic transient K(+) current modulated by arachidonic acid regulates synaptic integration and threshold for LTP induction in hippocampal pyramidal cells. Proc Natl Acad Sci U S A 99:10144-10149.

Rangroo Thrane V, Thrane AS, Plog BA, Thiyagarajan M, Iliff JJ, Deane R, Nagelhus EA, Nedergaard M (2013a) Paravascular microcirculation facilitates rapid lipid transport and astrocyte signaling in the brain. Sci Rep 3:2582.

Rangroo Thrane V, Thrane AS, Wang F, Cotrina ML, Smith NA, Chen M, Xu Q, Kang N, Fujita T, Nagelhus EA, Nedergaard M (2013b) Ammonia triggers neuronal disinhibition and seizures by impairing astrocyte potassium buffering. Nature medicine 19:1643-1648.

Rosenegger DG, Tran CH, Wamsteeker Cusulin JI, Gordon GR (2015) Tonic Local Brain Blood Flow Control by Astrocytes Independent of Phasic Neurovascular Coupling. The Journal of neuroscience : the official journal of the Society for Neuroscience 35:13463-13474.

Sang N, Zhang J, Marcheselli V, Bazan NG, Chen C (2005) Postsynaptically synthesized prostaglandin E2 (PGE2) modulates hippocampal synaptic transmission via a presynaptic PGE2 EP2 receptor. J Neurosci 25:9858-9870.

Schaeffer EL, Gattaz WF (2007) Requirement of hippocampal phospholipase A2 activity for long-term memory retrieval in rats. J Neural Transm 114:379-385.

Seegers HC, Gross RW, Boyle WA (2002) Calcium-independent phospholipase A(2)-derived arachidonic acid is essential for endothelium-dependent relaxation by acetylcholine. $\mathrm{J}$ Pharmacol Exp Ther 302:918-923.

Sekiyama N, Mizuta S, Hori A, Kobayashi S (1995) Prostaglandin E2 facilitates excitatory synaptic transmission in the nucleus tractus solitarii of rats. Neurosci Lett 188:101-104.

Shigetomi E, Bowser DN, Sofroniew MV, Khakh BS (2008) Two forms of astrocyte calcium excitability have distinct effects on NMDA receptor-mediated slow inward currents in pyramidal neurons. J Neurosci 28:6659-6663.

Silva GA, Theriault E, Mills LR, Pennefather PS, Feeney CJ (1999) Group I and II metabotropic glutamate receptor expression in cultured rat spinal cord astrocytes. Neurosci Lett 263:117-120.

Sinclair AJ (1975) Long-chain polyunsaturated fatty acids in the mammalian brain. The Proceedings of the Nutrition Society 34:287-291. 
Singaravelu K, Lohr C, Deitmer JW (2006) Regulation of store-operated calcium entry by calcium-independent phospholipase A2 in rat cerebellar astrocytes. J Neurosci 26:95799592.

Smith NA, Bekar LK, Nedergaard M (2019) Astrocytic Endocannabinoids Mediate Hippocampal Transient Heterosynaptic Depression. Neurochem Res.

Smith NA, Kress BT, Lu Y, Chandler-Militello D, Benraiss A, Nedergaard M (2018) Fluorescent $\mathrm{Ca}(2+)$ indicators directly inhibit the Na,K-ATPase and disrupt cellular functions. Sci Signal 11.

Srinivasan R, Huang BS, Venugopal S, Johnston AD, Chai H, Zeng H, Golshani P, Khakh BS (2015) $\mathrm{Ca}(2+)$ signaling in astrocytes from Ip3r2(-/-) mice in brain slices and during startle responses in vivo. Nat Neurosci 18:708-717.

Stella N, Tence M, Glowinski J, Premont J (1994) Glutamate-evoked release of arachidonic acid from mouse brain astrocytes. J Neurosci 14:568-575.

Stella N, Estelles A, Siciliano J, Tence M, Desagher S, Piomelli D, Glowinski J, Premont J (1997) Interleukin-1 enhances the ATP-evoked release of arachidonic acid from mouse astrocytes. J Neurosci 17:2939-2946.

Strokin M, Sergeeva M, Reiser G (2003) Docosahexaenoic acid and arachidonic acid release in rat brain astrocytes is mediated by two separate isoforms of phospholipase A2 and is differently regulated by cyclic AMP and Ca2+. Br J Pharmacol 139:1014-1022.

Strokin M, Sergeeva M, Reiser G (2007) Prostaglandin synthesis in rat brain astrocytes is under the control of the n-3 docosahexaenoic acid, released by group VIB calcium-independent phospholipase A2. J Neurochem 102:1771-1782.

Strokin M, Chechneva O, Reymann KG, Reiser G (2006) Neuroprotection of rat hippocampal slices exposed to oxygen-glucose deprivation by enrichment with docosahexaenoic acid and by inhibition of hydrolysis of docosahexaenoic acid-containing phospholipids by calcium independent phospholipase A2. Neuroscience 140:547-553.

Sun GY, Xu J, Jensen MD, Simonyi A (2004) Phospholipase A2 in the central nervous system: implications for neurodegenerative diseases. Journal of lipid research 45:205-213.

Sun GY, Xu J, Jensen MD, Yu S, Wood WG, Gonzalez FA, Simonyi A, Sun AY, Weisman GA (2005) Phospholipase A2 in astrocytes: responses to oxidative stress, inflammation, and G protein-coupled receptor agonists. Mol Neurobiol 31:27-41.

Sun W, McConnell E, Pare JF, Xu Q, Chen M, Peng W, Lovatt D, Han X, Smith Y, Nedergaard M (2013) Glutamate-dependent neuroglial calcium signaling differs between young and adult brain. Science 339:197-200.

Takano T, Tian GF, Peng W, Lou N, Libionka W, Han X, Nedergaard M (2006) Astrocytemediated control of cerebral blood flow. Nat Neurosci 9:260-267.

Talbot MJ, Sayer RJ (1996) Intracellular QX-314 inhibits calcium currents in hippocampal CA1 pyramidal neurons. Journal of neurophysiology 76:2120-2124.

Tamaru Y, Nomura S, Mizuno N, Shigemoto R (2001) Distribution of metabotropic glutamate receptor mGluR3 in the mouse CNS: differential location relative to pre- and postsynaptic sites. Neuroscience 106:481-503.

Tang W, Szokol K, Jensen V, Enger R, Trivedi CA, Hvalby O, Helm PJ, Looger LL, Sprengel R, Nagelhus EA (2015) Stimulation-evoked Ca2+ signals in astrocytic processes at hippocampal CA3-CA1 synapses of adult mice are modulated by glutamate and ATP. The Journal of neuroscience : the official journal of the Society for Neuroscience 35:3016-3021. 
Tay HK, Melendez AJ (2004) Fcgamma RI-triggered generation of arachidonic acid and eicosanoids requires iPLA2 but not cPLA2 in human monocytic cells. J Biol Chem 279:22505-22513.

van Tol-Steye H, Lodder JC, Mansvelder HD, Planta RJ, van Heerikhuizen H, Kits KS (1999) Roles of G-protein beta gamma, arachidonic acid, and phosphorylation inconvergent activation of an S-like potassium conductance by dopamine, Ala-Pro-Gly-Trp-NH2, and Phe-Met-Arg-Phe-NH2. J Neurosci 19:3739-3751.

Villarroel A, Schwarz TL (1996) Inhibition of the Kv4 (Shal) family of transient K+ currents by arachidonic acid. The Journal of neuroscience : the official journal of the Society for Neuroscience 16:2522-2532.

Wang F, Smith NA, Xu Q, Fujita T, Baba A, Matsuda T, Takano T, Bekar L, Nedergaard M (2012) Astrocytes modulate neural network activity by $\mathrm{Ca}(2)+$-dependent uptake of extracellular K+. Sci Signal 5:ra26.

Wang X, Lou N, Xu Q, Tian GF, Peng WG, Han X, Kang J, Takano T, Nedergaard M (2006) Astrocytic $\mathrm{Ca} 2+$ signaling evoked by sensory stimulation in vivo. Nature neuroscience 9:816-823.

Wilson RJ, Giblin GM, Roomans S, Rhodes SA, Cartwright KA, Shield VJ, Brown J, Wise A, Chowdhury J, Pritchard S, Coote J, Noel LS, Kenakin T, Burns-Kurtis CL, Morrison V, Gray DW, Giles H (2006) GW627368X ((N-\{2-[4-(4,9-diethoxy-1-oxo-1,3-dihydro-2Hbenzo[f]isoindol-2-yl)phenyl]acetyl $\}$ benzene sulphonamide): a novel, potent and selective prostanoid EP4 receptor antagonist. Br J Pharmacol 148:326-339.

Windrem MS, Nunes MC, Rashbaum WK, Schwartz TH, Goodman RA, McKhann G, 2nd, Roy NS, Goldman SA (2004) Fetal and adult human oligodendrocyte progenitor cell isolates myelinate the congenitally dysmyelinated brain. Nat Med 10:93-97.

Windrem MS, Schanz SJ, Guo M, Tian GF, Washco V, Stanwood N, Rasband M, Roy NS, Nedergaard M, Havton LA, Wang S, Goldman SA (2008) Neonatal chimerization with human glial progenitor cells can both remyelinate and rescue the otherwise lethally hypomyelinated shiverer mouse. Cell stem cell 2:553-565.

Winstead MV, Balsinde J, Dennis EA (2000) Calcium-independent phospholipase A(2): structure and function. Biochimica et biophysica acta 1488:28-39.

Wolf MJ, Gross RW (1996) The calcium-dependent association and functional coupling of calmodulin with myocardial phospholipase A2. Implications for cardiac cycle-dependent alterations in phospholipolysis. J Biol Chem 271:20989-20992.

Wolf MJ, Wang J, Turk J, Gross RW (1997) Depletion of intracellular calcium stores activates smooth muscle cell calcium-independent phospholipase A2. A novel mechanism underlying arachidonic acid mobilization. J Biol Chem 272:1522-1526.

Wroblewska B, Wroblewski JT, Pshenichkin S, Surin A, Sullivan SE, Neale JH (1997) Nacetylaspartylglutamate selectively activates mGluR3 receptors in transfected cells. J Neurochem 69:174-181.

Yang HC, Mosior M, Ni B, Dennis EA (1999) Regional distribution, ontogeny, purification, and characterization of the $\mathrm{Ca} 2+-i n d e p e n d e n t$ phospholipase $\mathrm{A} 2$ from rat brain. $\mathrm{J}$ Neurochem 73:1278-1287.

Yang Y, Ge W, Chen Y, Zhang Z, Shen W, Wu C, Poo M, Duan S (2003) Contribution of astrocytes to hippocampal long-term potentiation through release of D-serine. Proc Natl Acad Sci U S A 100:15194-15199. 
Yu X, Taylor AMW, Nagai J, Golshani P, Evans CJ, Coppola G, Khakh BS (2018) Reducing Astrocyte Calcium Signaling In Vivo Alters Striatal Microcircuits and Causes Repetitive Behavior. Neuron 99:1170-1187 e1179.

Zonta M, Angulo MC, Gobbo S, Rosengarten B, Hossmann KA, Pozzan T, Carmignoto G (2003) Neuron-to-astrocyte signaling is central to the dynamic control of brain microcirculation. Nat Neurosci 6:43-50. 


\section{A}
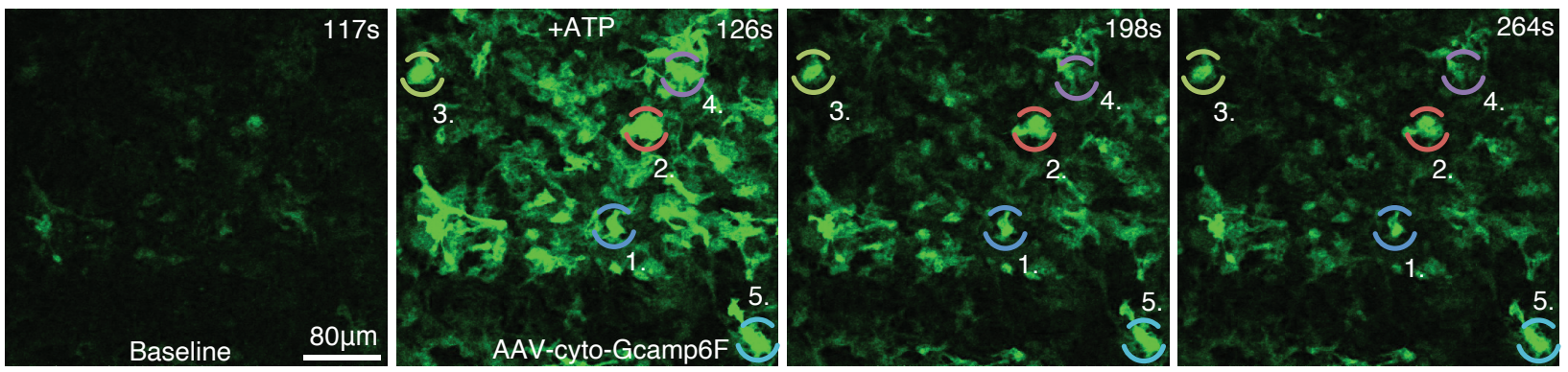

B

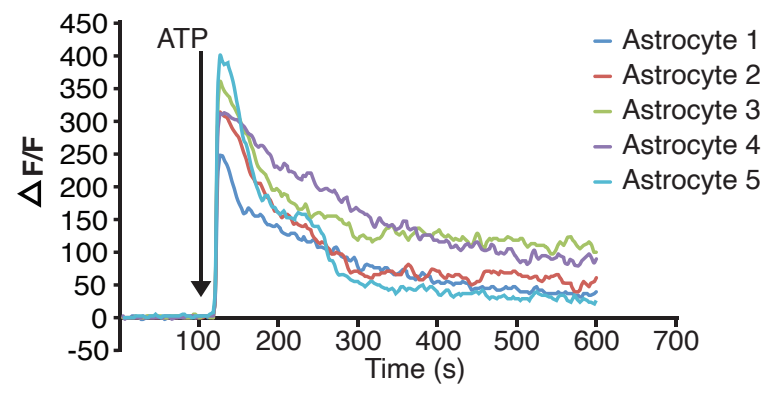

C

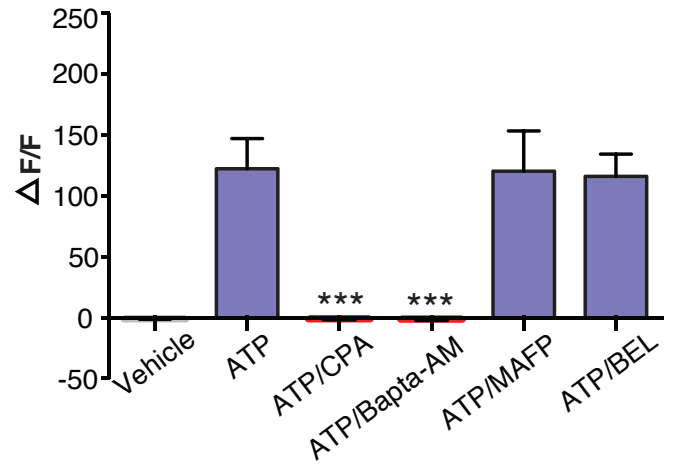


A

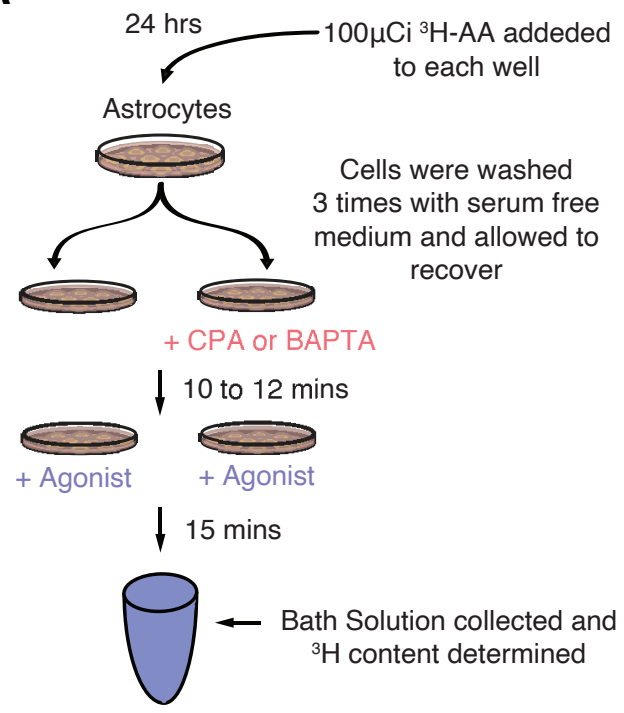

B

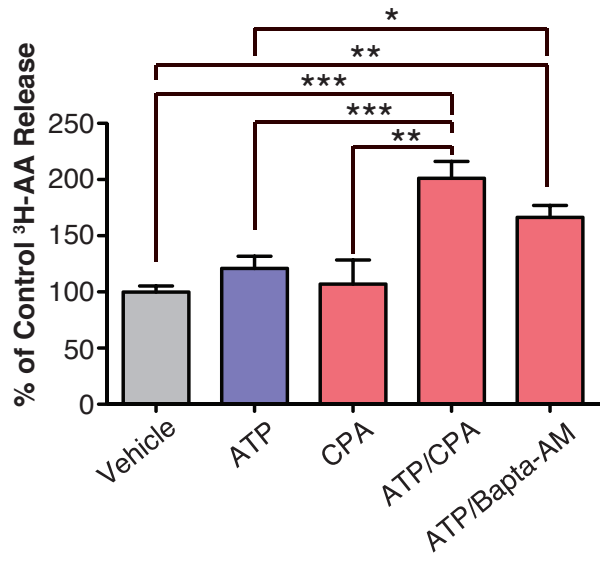

C

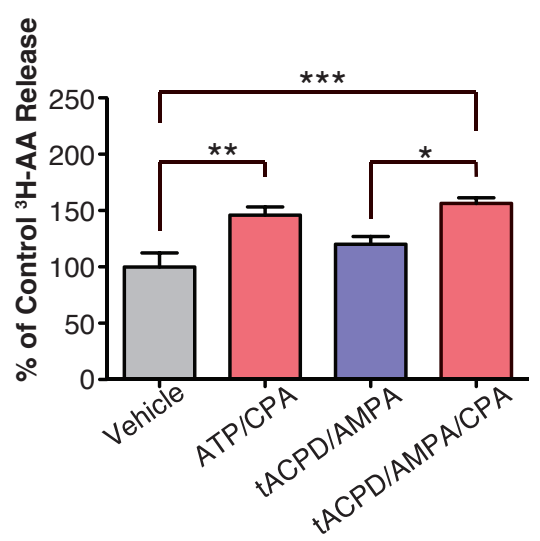

D

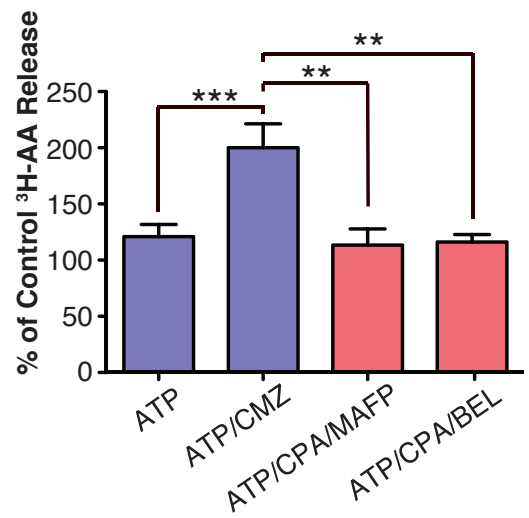

Figure 2 
bioRxiv preprint doi: https://doi.org/10.1101/2020.01.12.903393; this version posted March 31, 2021. The copyright holder for this preprint (which was not certified by peer review) is the author/funder, who has granted bioRxiv a license to display the preprint in perpetuity. It is made available under aCC-BY-NC-ND 4.0 International license.

Relative differences of lipid levels in astrocytes treated with CPA and ATP compared to vehicle

\begin{tabular}{|c|c|}
\hline Prostaglandins & \\
\hline $\mathrm{PGE}_{2}$ & 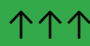 \\
\hline \multicolumn{2}{|l|}{ Free fatty acids } \\
\hline \multirow{2}{*}{$\begin{array}{l}\text { Arachidonic acid } \\
\text { Linoleic acid }\end{array}$} & $\uparrow$ \\
\hline & n.d. \\
\hline \multicolumn{2}{|l|}{ 2-arachidonoyl-sn-glycerol } \\
\hline \multirow{3}{*}{$\begin{array}{l}\text { 2-arachidonoyl-sn-glycerol } \\
\text { 2-linoleoyl-sn-glycerol } \\
\text { 2-oleoyl-sn-glycerol }\end{array}$} & $\uparrow$ \\
\hline & n.d. \\
\hline & n.d. \\
\hline \multicolumn{2}{|l|}{$N$-acyl ethanolamine } \\
\hline \multirow{6}{*}{$\begin{array}{l}N \text {-palmitoyl ethanolamine } \\
N \text {-stearoyl ethanolamine } \\
N \text {-oleoyl ethanolamine } \\
N \text {-linoleoyl ethanolamine } \\
N \text {-arachidonoyl ethanolamine } \\
N \text {-docosahexaenoyl ethanolamine }\end{array}$} & $\uparrow \uparrow$ \\
\hline & $\uparrow \uparrow$ \\
\hline & $\uparrow \uparrow$ \\
\hline & n.d. \\
\hline & $\uparrow$ \\
\hline & 个个 \\
\hline \multicolumn{2}{|l|}{$N$-acyl glycine } \\
\hline \multirow{5}{*}{$\begin{array}{l}N \text {-palmitoyl glycine } \\
N \text {-stearoyl glycine } \\
N \text {-oleoyl glycine } \\
N \text {-linoleoyl glycine } \\
N \text {-arachidonoyl glycine }\end{array}$} & n.d. \\
\hline & $\uparrow$ \\
\hline & $\uparrow$ \\
\hline & n.d. \\
\hline & n.d. \\
\hline \multicolumn{2}{|l|}{$N$-acyl serine } \\
\hline \multirow{4}{*}{$\begin{array}{l}N \text {-palmitoyl serine } \\
N \text {-stearoyl serine } \\
N \text {-oleoyl serine } \\
N \text {-arachidonoyl serine }\end{array}$} & n.d. \\
\hline & n.d. \\
\hline & n.d. \\
\hline & n.d. \\
\hline \multicolumn{2}{|l|}{$N$-acyl taurine } \\
\hline$N$-arachidonoyl taurine & $\uparrow$ \\
\hline \multicolumn{2}{|l|}{$N$-acyl tyrosine } \\
\hline \multirow{5}{*}{$\begin{array}{l}N \text {-palmitoyl tyrosine } \\
N \text {-stearoyl tyrosine } \\
N \text {-oleoyl tyrosine } \\
N \text {-arachidonoyl tyrosine } \\
N \text {-docosahexaenoyl tyrosine }\end{array}$} & $\uparrow$ \\
\hline & $\uparrow$ \\
\hline & $\uparrow$ \\
\hline & n.d. \\
\hline & $\uparrow$ \\
\hline \multicolumn{2}{|l|}{$N$-acyl tryptophan } \\
\hline \multirow{3}{*}{$\begin{array}{l}N \text {-palmitoyl tryptophan } \\
N \text {-oleoyl tryptophan } \\
N \text {-docosahexaenoyl tryptophan }\end{array}$} & n.d. \\
\hline & n.d. \\
\hline & n.d. \\
\hline
\end{tabular}

\begin{tabular}{l|l|}
\multicolumn{2}{c}{ Magnitude Differences } \\
\hline 2-2.99 times higher & $\uparrow \uparrow \uparrow$ \\
\hline $1.50-1.99$ times higher & $\uparrow \uparrow$ \\
\hline \begin{tabular}{l} 
1-1.49 times higher \\
\multicolumn{1}{c|}{ Significant Differences }
\end{tabular} \\
\hline Significant increase $p<0.05$ & \\
\hline Trending increase $p=0.05-0.10$ & \\
\hline no difference between groups & n.d. \\
\hline
\end{tabular}

2.E+04

2.E+04 10pmol PGE2 standard

2.E+04

1.E+04 HPLC/MS/MS multiple reaction

7. 1.E+04 monitoring method scanning for

응

$1 . E+04$

$8 . E+03$

mith $[-\mathrm{H}] 315$ fragment ions

$6 . E+03$

4.E+03

2. $\mathrm{E}+03$

$0 . \mathrm{E}+00$

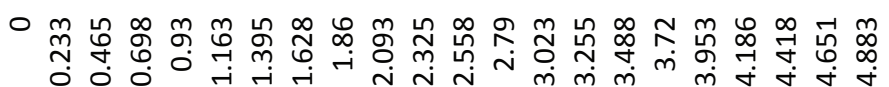

C

Time (minutes)

3.E+05

2.E+05

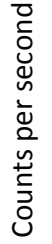

2.E+05

$1 . E+05$

5.E+04

$0 . \mathrm{E}+00$

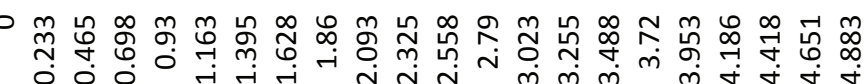

D

Time (minutes)

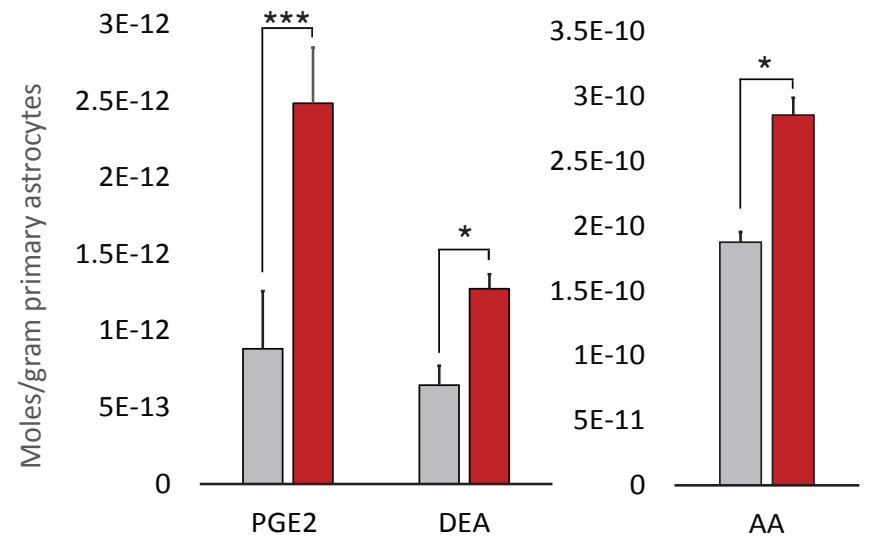

$\square$ Veh
CPA/ATP stimulated astrocytic lipid extract using [-H]351/315 MRM on $40 \%$ partial purification fraction 
A

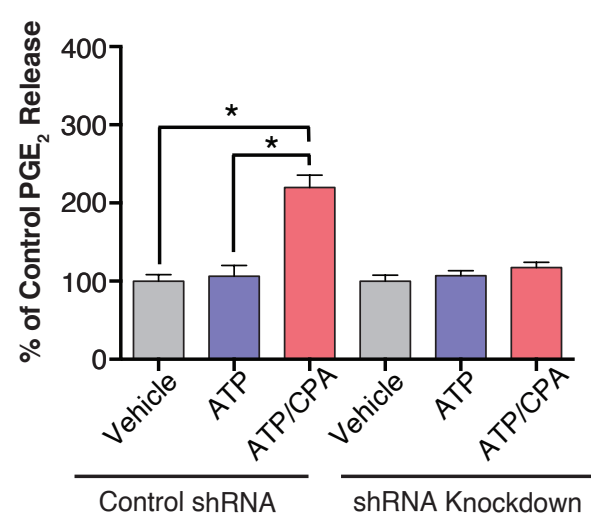

D

.

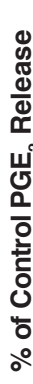

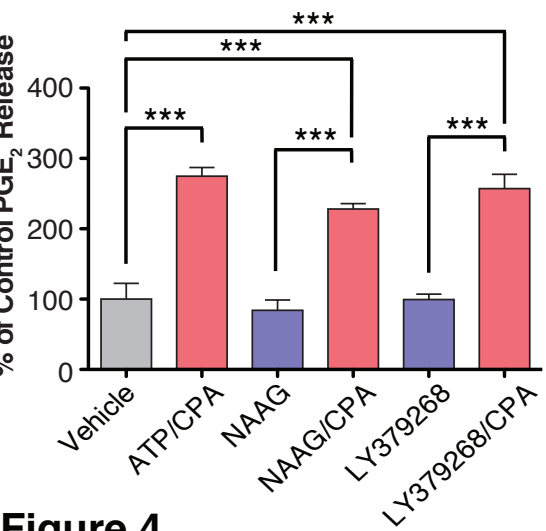

Figure 4

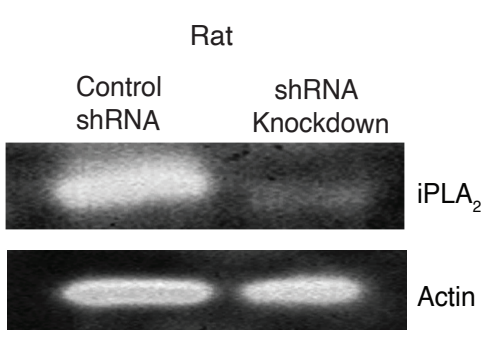

E

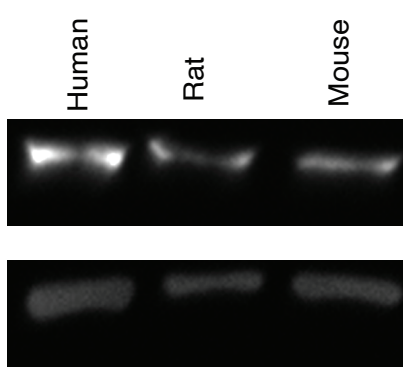

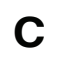

Rat

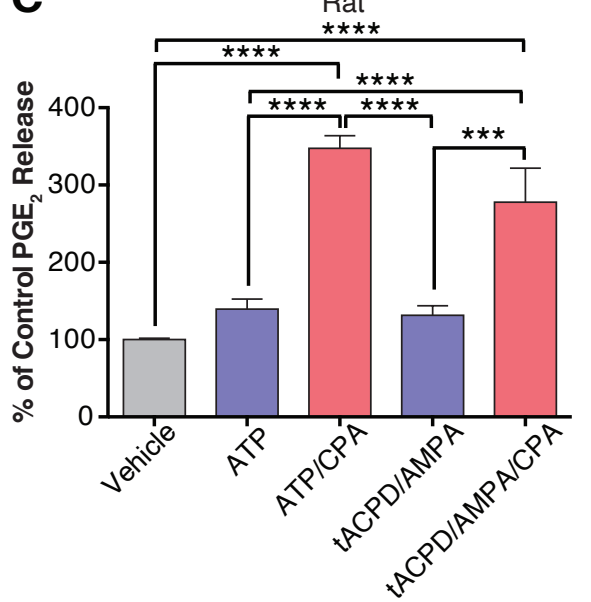

F

Human

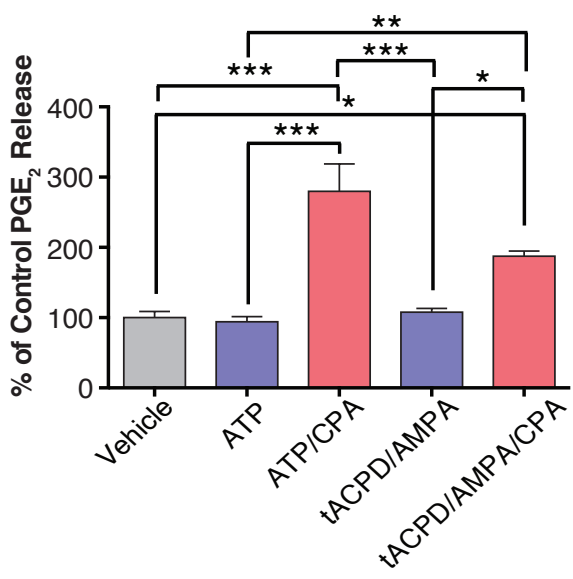



available under aCC-BY-NC-ND 4.0 International license.

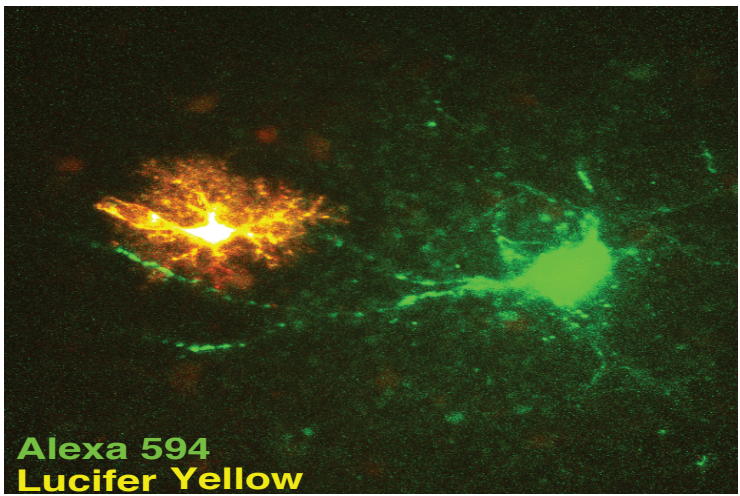

Patched astrocyte and neuron

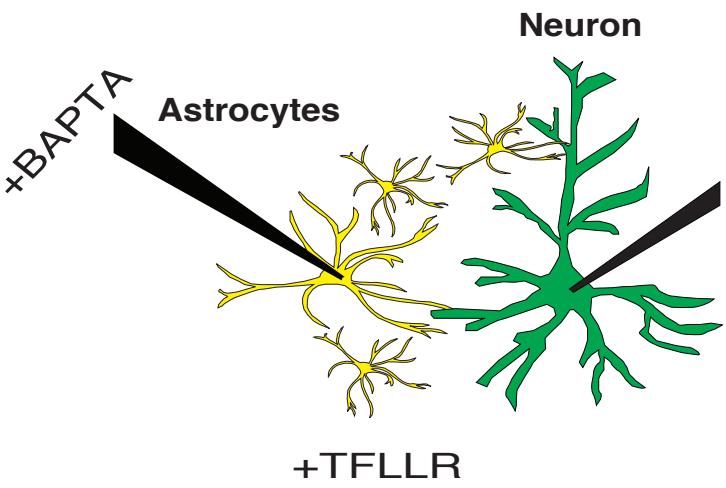

C

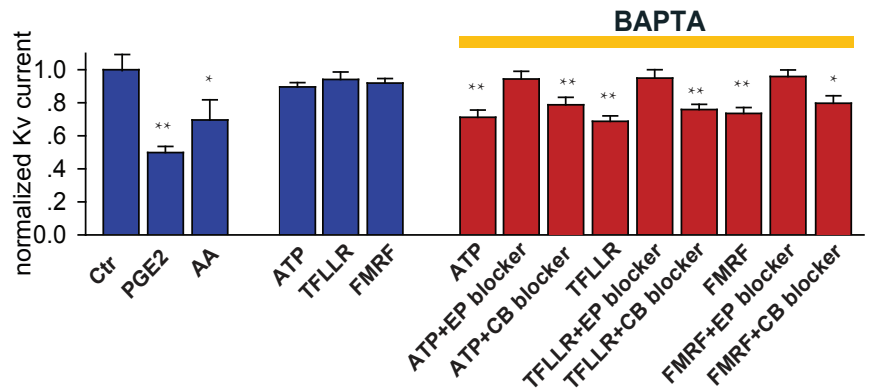

B
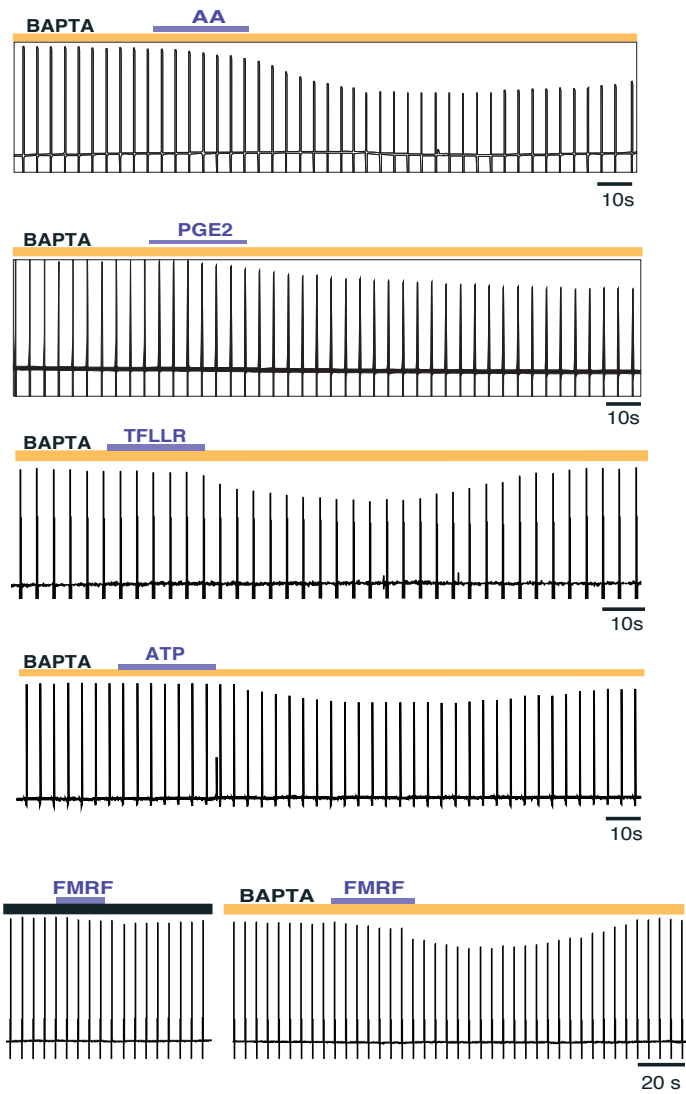
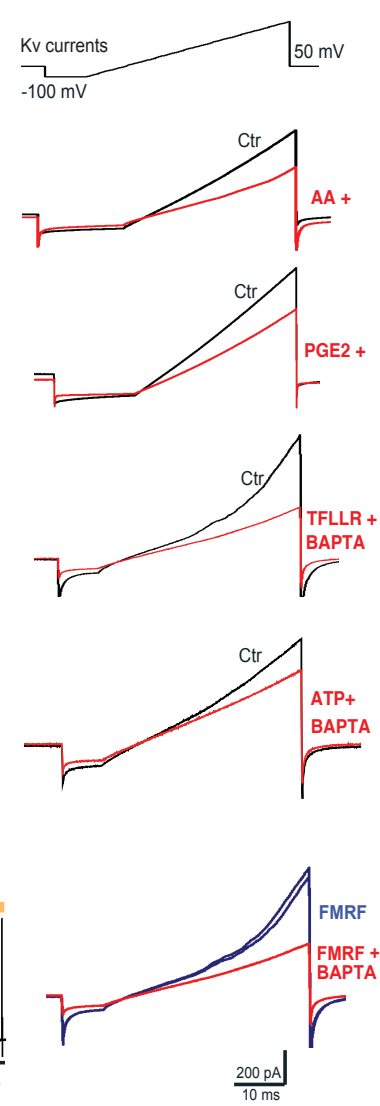
bioRxiv preprint doi: https://doi.org/10.1101/2020.01.12 903393; this version posted March 31, 2021. The copyright holder for this preprint (which was not certified by peer review) is the author/funder, who has granted bioRxiv a license to display the preprint in perpetuity. It is made available under aCC-BY-NC-ND 4.0 International license.

A
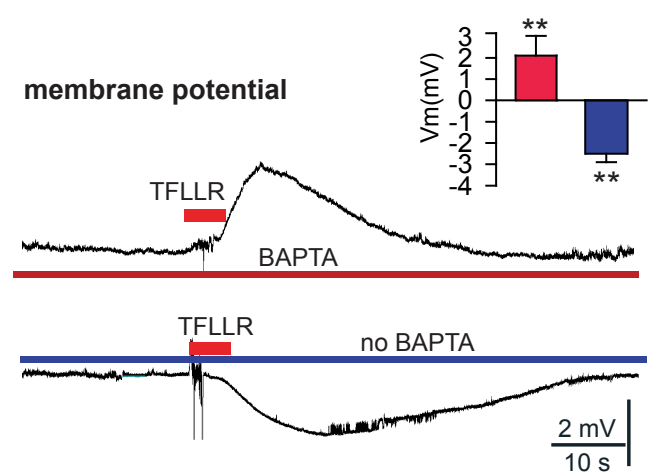

B

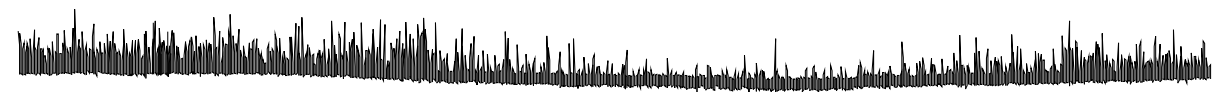

$\overline{T F L L R}$

C MEPSP

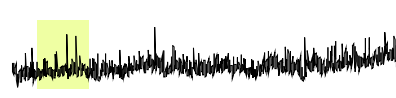

$\overline{\text { TFLLR }}$ BAPTA $1 \mathrm{~s} / 3 \mathrm{mV}$
$10 \mathrm{~s} 3 \mathrm{mV}$
D

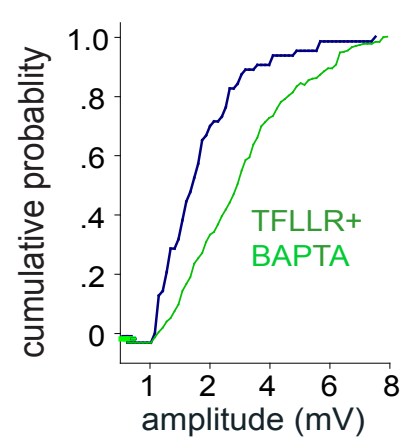

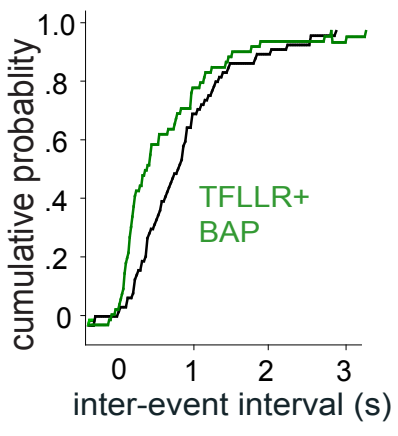

E

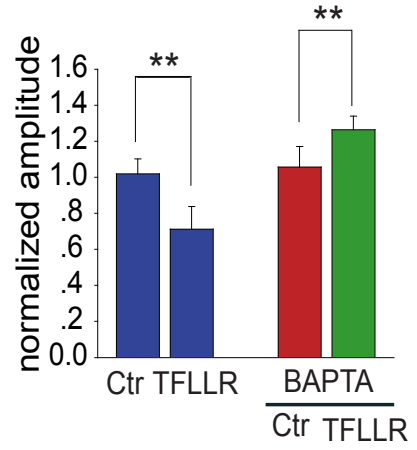

Figure 6 
A

$\mathrm{Ca}^{2+}-$ Independent Pathway

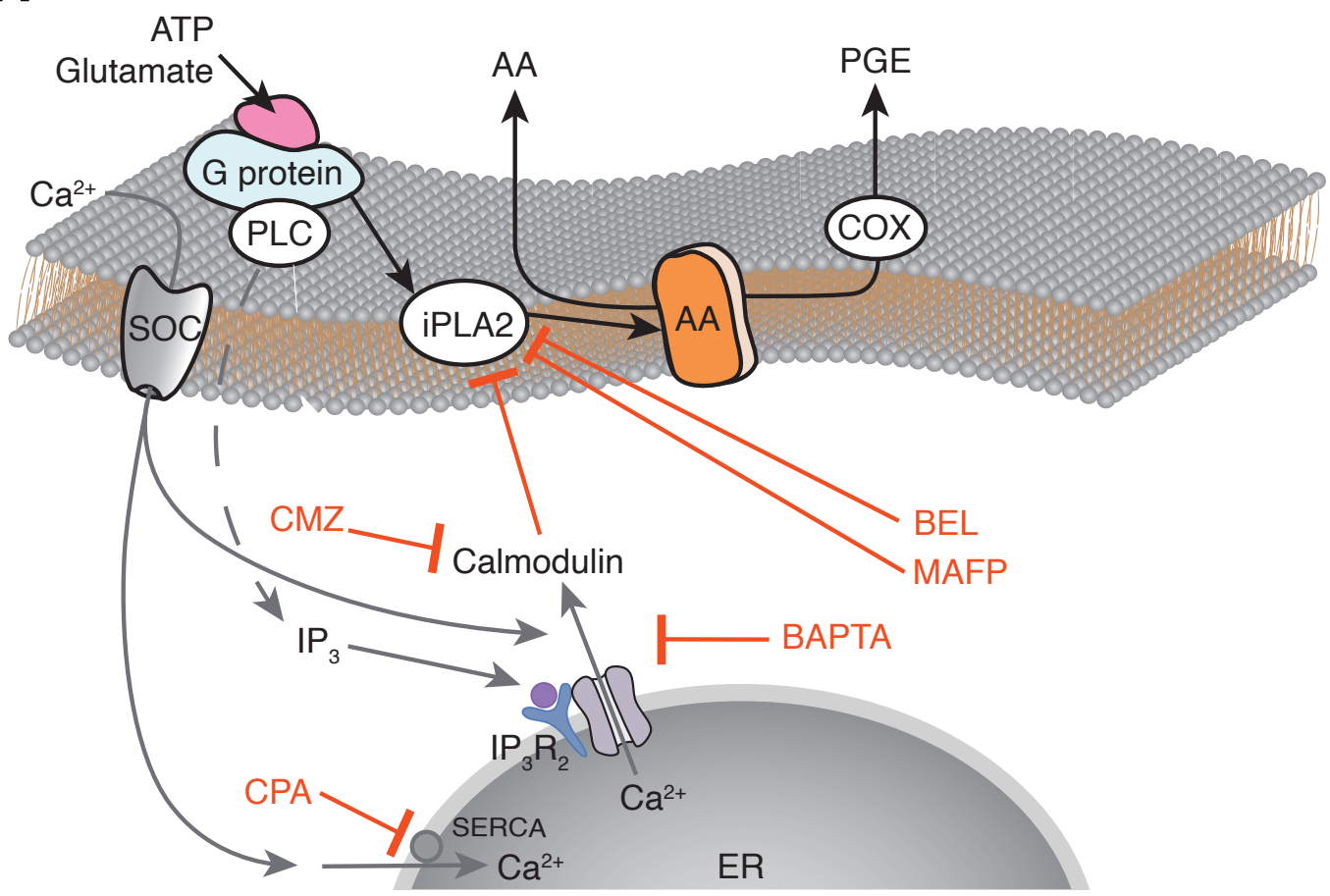

B

$\mathrm{Ca}^{2+}$-Dependent Pathway

ATP

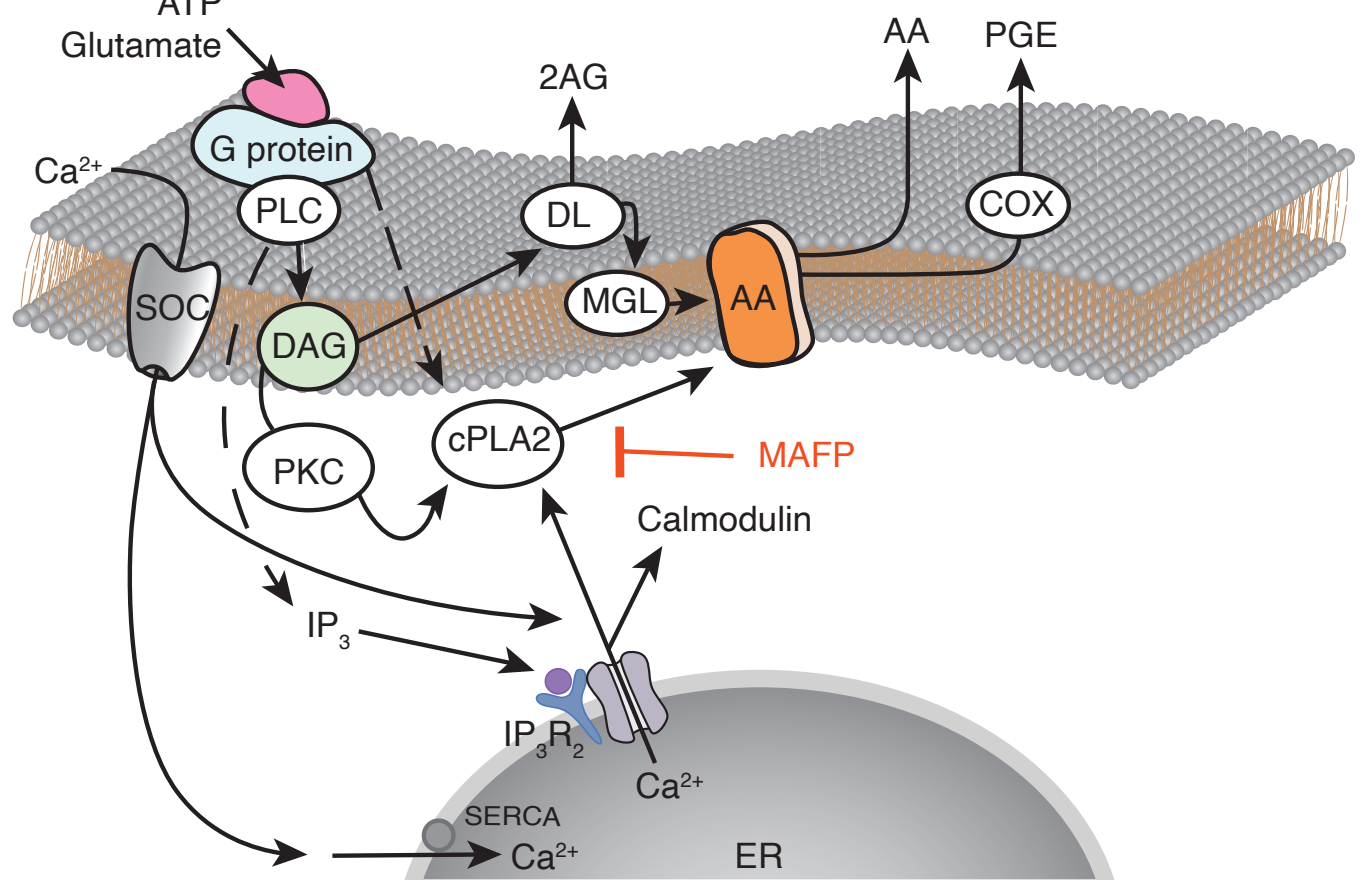

